\title{
Front Matter: Volume 10014
}

, "Front Matter: Volume 10014," Proc. SPIE 10014, Laser-Induced Damage in Optical Materials 2016, 1001401 (29 November 2016); doi:

10.1117/12.2268110

SPIE. Event: SPIE Laser Damage, 2016, Boulder, Colorado, United States 


\section{8th ANNUAL LASER DAMAGE SYMPOSIUM Proceedings}

\section{SPIE. DASER}

\section{LASER-INDUCED DAMAGE IN OPTICAL MATERIALS 2016}

\section{5-28 September 2016 \\ Boulder, Colorado}

Editors

Gregory J. Exarhos, Vitaly E. Gruzdev, Joseph A. Menapace, Detlev Ristau, MJ Soileau

$$
\text { Organized by }
$$

SPIE

Cosponsored by

Laser Components GmbH (Germany)

Spica Technologies, Inc. (United States)

ZC Optoelectronic Technologies, Ltd. (China)

\section{Cooperating Organizations}

CREOL \& FPCE, College of Optics and Photonics, University of Central Florida (United States)

Laser Zentrum Hannover e.V. (Germany)

Lawrence Livermore National Laboratory (United States)

University of Missouri-Columbia (United States)

Pacific Northwest National Laboratory (United States)

Laboratory for Laser Energetics, University of Rochester (United States)

Office of Naval Research (United States)

Founding Organizers

Arthur H. Guenther and Alexander J. Glass

Published by

SPIE 
The papers included in this volume were part of the technical conference cited on the cover and title page. Papers were selected and subject to review by the editors and conference program committee. Some conference presentations may not be available for publication. The papers published in these proceedings reflect the work and thoughts of the authors and are published herein as submitted. The publisher is not responsible for the validity of the information or for any outcomes resulting from reliance thereon.

Please use the following format to cite material from these proceedings:

Author(s), "Title of Paper," in Laser-Induced Damage in Optical Materials 2016, edited by Gregory J. Exarhos, Vitaly E. Gruzdev, Joseph A. Menapace, Detlev Ristau, MJ Soileau, Proceedings of SPIE Vol. 10014 (SPIE, Bellingham, WA, 2016) Six-Digit Article CID Number.

ISSN: 0277-786X

ISSN: 1996-756X (electronic)

ISBN: 9781510604360

ISBN: 9781510604377 (electronic)

Published by

SPIE

P.O. Box 10, Bellingham, Washington 98227-0010 USA

Telephone +1 3606763290 (Pacific Time) F Fax +1 3606471445

SPIE.org

Copyright (C) 2016, Society of Photo-Optical Instrumentation Engineers.

Copying of material in this book for internal or personal use, or for the internal or personal use of specific clients, beyond the fair use provisions granted by the U.S. Copyright Law is authorized by SPIE subject to payment of copying fees. The Transactional Reporting Service base fee for this volume is $\$ 18.00$ per article (or portion thereof), which should be paid directly to the Copyright Clearance Center (CCC), 222 Rosewood Drive, Danvers, MA 01923. Payment may also be made electronically through CCC Online at copyright.com. Other copying for republication, resale, advertising or promotion, or any form of systematic or multiple reproduction of any material in this book is prohibited except with permission in writing from the publisher. The CCC fee code is $0277-786 \mathrm{X} / 16 / \$ 18.00$.

Printed in the United States of America.

Publication of record for individual papers is online in the SPIE Digital Library.

\section{SPIE. DIGITAL}

SPIEDigitalLibrary.org

Paper Numbering: Proceedings of SPIE follow an e-First publication model. A unique citation identifier (CID) number is assigned to each article at the time of publication. Utilization of CIDs allows articles to be fully citable as soon as they are published online, and connects the same identifier to all online and print versions of the publication. SPIE uses a sevendigit CID article numbering system structured as follows:

- The first five digits correspond to the SPIE volume number.

- The last two digits indicate publication order within the volume using a Base 36 numbering system employing both numerals and letters. These two-number sets start with $00,01,02,03,04,05,06,07,08$, $09,0 \mathrm{~A}, 0 \mathrm{~B} \ldots 0 \mathrm{Z}$, followed by 10-1Z, 20-2Z, etc. The CID Number appears on each page of the manuscript. 


\title{
Contents
}

\author{
vii Authors \\ ix Conference Committee \\ xi Symposium Welcome \\ J. A. Menapace \\ xiii Summary of Meeting \\ V. E. Gruzdev
}

\section{SURFACES, MIRRORS, AND CONTAMINATION I}

$1001402 \quad$ Laser-matter coupling mechanisms governing particulate-induced damage on optical surfaces (Keynote Paper) [10014-1]

1001404 Entry and exit facet laser damage of optical windows with random antireflective surface structures [10014-3]

\section{SURFACES, MIRRORS, AND CONTAMINATION II}

1001405 Effects of chemical etching on the surface quality and the laser induced damage threshold of fused silica optics [10014-4]

1001406 Laser-induced Hertzian fractures on the exit surface of silica glass deposited with metal micro-spheres [10014-5]

1001407 Development of a laser damage growth mitigation process, based on $\mathrm{CO}_{2}$ laser micro processing, for the Laser MegaJoule fused silica optics [10014-6]

1001408 Verification for robustness to laser-induced damage for the Aladin instrument on the ADM-Aeolus satellite [10014-7]

THIN FILMS I

1001409 Nanosecond laser-induced damage of high-reflection coatings: NUV through NIR (Keynote Paper) [10014-8]

10014 0A Laser-induced damage of $\mathrm{F}_{-} \mathrm{SiO}_{2}$ protected fluoride-based AR coatings on subsurface-damage-free $\mathrm{CaF}_{2}$ at $193 \mathrm{~nm}[10014-10]$

\section{THIN FILMS II}

10014 0C Electronic quantization in dielectric nanolaminates [10014-13] 
10014 0D Few-cycle pulse laser-induced damage of thin films in air and vacuum ambience (Best Paper Award) [10014-14]

10014 0E 40-fs broadband low dispersion mirror thin film damage competition [10014-15]

\section{MATERIALS AND MEASUREMENTS I}

10014 0F Metrology of fused silica (Keynote Paper, Best Paper Award) [10014-16]

$10014 \mathrm{OH} \quad$ Nanosecond laser-induced damage of transparent conducting ITO film at 1064nm [10014-18]

\section{MATERIALS AND MEASUREMENTS II}

10014 OM Laser conditioning mechanism revealed by defect and absorption variation in the bulk and at the surface of KDP/DKDP crystals [10014-23]

\section{MATERIALS AND MEASUREMENTS III}

$1001400 \quad$ Comparison of different LIDT testing protocols for PW and multi-PW class high-reflectivity coatings [10014-25]

\section{MATERIALS AND MEASUREMENTS IV}

10014 OS Plume dynamics from UV pulsed ablation of Al and Ti [10014-29]

10014 0T Laser induced damage threshold of optical fibers under ns pulses [10014-30]

MINI-SYMPOSIUM: REVIEW OF LARGE-SCALE, HIGH-POWER LASER FACILITY PROJECTS II

10014 0Z Sandia's Z-Backlighter Laser Facility (Plenary Presentation) [10014-36]

\section{FUNDAMENTAL MECHANISMS I}

1001413 Investigation of mechanisms leading to laser damage morphology (Keynote Paper) [10014-39]

1001414 Morphology and mechanisms of picosecond ablation of metal films on fused silica substrates [10014-40]

1001417 Time-resolved microscopy studies of laser damage dynamics at 0.5-1ps, 1030nm [10014-43]

\section{FUNDAMENTAL MECHANISMS II}

10014 1A First-principles calculations for initial electronic excitation in dielectrics induced by intense femtosecond laser pulses [10014-46]

10014 1B Dual wavelength laser damage mechanisms in the ultra-short pulse regime [10014-47]

iv 
10014 1C Ultrafast polychromatic ionization of dielectric solids [10014-48]

POSTER SESSION: SURFACES, MIRRORS, AND CONTAMINATION

10014 1F Characterization of the polishing induced contamination of fused silica optics [10014-52]

10014 1H Damage behavior of Nd:glass of high-power disk amplifier medium in ICF Facility [10014-75]

\section{POSTER SESSION: MATERIALS AND MEASUREMENTS}

10014 1J Laser-induced bulk damage of silica glass at 355nm and 266nm [10014-55]

$100141 \mathrm{~K}$ Investigation of laser-induced ablation of ceramic materials for spaceborne applications [10014-56]

10014 1L Investigation of the ageing effects exhibited by AR coatings exposed to ultraviolet laser irradiation [10014-57]

$100141 \mathrm{~N} \quad$ Characterization of NLO crystal absorption for wavelengths $1 \omega$ to $4 \omega$ (Best Paper Award) [10014-59]

10014 1Q Laser remote heating in vacuum environment to study temperature dependence of optical properties for bulk materials [10014-62]

\section{POSTER SESSION: FUNDAMENTAL MECHANISMS}

$100141 \mathrm{~T} \quad$ Influence of the size and concentration of precursor on laser damage performance in KDP crystal [10014-64]

$100141 \mathrm{U} \quad$ Probing the dynamics of the interaction between few-cycle laser pulses and single crystal (100) Si and GaAs near the laser-induced damage threshold [10014-65]

10014 1W Finite difference time domain method for simulation of damage initiation in thin film coatings [10014-67]

$100141 \mathrm{X}$ Investigations to highlight the first stage of UV-fatigue effect in silica [10014-78]

POSTER SESSION: THIN FILMS

$100141 \mathrm{Y}$ Study of the picosecond laser damage in $\mathbf{H f O}_{2} / \mathrm{SiO}_{2}$-based thin-film coatings in vacuum [10014-68]

$100141 \mathrm{Z}$ Improved LIDT values for dielectric dispersive compensating mirrors applying ternary composites [10014-69]

$1001421 \quad$ Comparison of ALD and IBS $\mathbf{A l}_{2} \mathbf{O}_{3}$ films for high power lasers [10014-71]

1001422 Impacts of $\mathrm{SiO}_{2}$ planarization on optical thin film properties and laser damage resistance [10014-72]

$1001424 \quad$ A study of metal-dielectric mirrors technology with regard to the laser-induced damage threshold [10014-74]

1001425 Use of $\mathrm{Al}_{2} \mathbf{O}_{3}$ layers for higher laser damage threshold at $22.5^{\circ}$ incidence, $\mathrm{S}$ polarization of a $527 \mathrm{~nm} / 1054$ nm dichroic coating (Best Paper Award) [10014-89] 
Proc. of SPIE Vol. 10014 1001401-6

Downloaded From: https://www.spiedigitallibrary.org/conference-proceedings-of-spie on 26 Apr 2023 Terms of Use: https://www.spiedigitallibrary.org/terms-of-use 


\section{Authors}

Numbers in the index correspond to the last two digits of the seven-digit citation identifier (CID) article numbering system used in Proceedings of SPIE. The first five digits reflect the volume number. Base 36 numbering is employed for the last two digits and indicates the order of articles within the volume. Numbers start with $00,01,02,03,04,05,06,07,08,09,0 \mathrm{~A}, 0 \mathrm{~B} \ldots 0 \mathrm{Z}$, followed by 10-1Z, 20-2Z, etc.

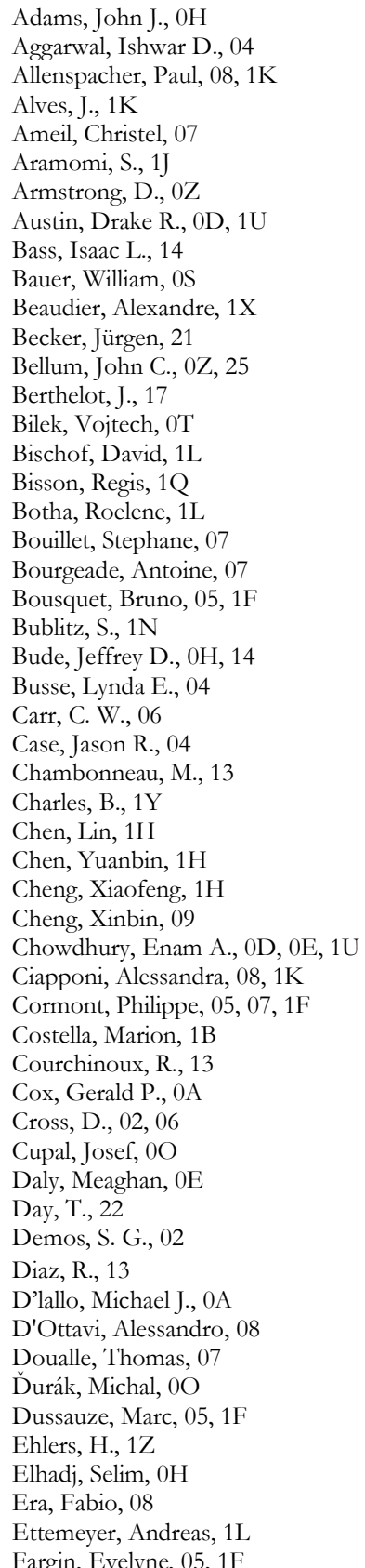

Feigenbaum, E., 02, 06

Fejer, M. M., 22

Field, Ella S., 0Z, 25

Folta, J., 22

Gallais, Laurent, 07, 0C, 17, 1Q

Geerke, P., OC

Geissel, M., 0Z

Grigutis, Robertas, 1W

Grua, P., 13

Guss, Gabe, 14

Gyamfi, Mark, 1B, 1C, 1Z

Hanus, Martin, 0T

Harris, C., 02

Haugan, Timothy, OS

$\mathrm{He}$, Pengfei, 09

$\mathrm{He}$, Shaobo, $1 \mathrm{H}$

Heese, C., $1 \mathrm{~K}$

Hippler, M., 1K

Hu, Guohang, 0M, 1T

Ivanov, T., $1 \mathrm{~K}$

Jankowska, E., 22

Jensen, Lars, 1B, 21

Jiao, Hongfei, 09

Jupé, M., 0C, 1C, $1 \mathrm{Z}$

Jürgens, Peter, 1B, 1C

Kafka, Kyle R. P., 0D, 0E, 1U

Kashiwagi, R., 1J

Keller, Wesley J., 14

Kimmel, M., 0Z

Kirchner, Matt, 0E

Kletecka, Damon E., 0Z, 25

Kozlov, A. A., $1 Y$

Kramer, Daniel, $0 \mathrm{O}$

Kühn, B., OF

Labrugère, Christine, $1 \mathrm{~F}$

Lamaignère, Laurent, 07, 13, 17

Lambert, Sébastien, 05, $1 \mathrm{~F}$

Lee, Jonathan R. I., $0 \mathrm{H}$

Li, Dawei, 0M

Liu, Hao, 21

Liu, Xiaofeng, $0 \mathrm{M}$

Longuet, Jean-Louis, $1 \mathrm{~F}$

Lucianetti, Antonio, 0T

$\mathrm{Ma}$, Bin, 09

Ma, Hongping, 09

Ma, Ping, 21

Markosyan, A., 22

Mateo, A. B., $1 \mathrm{~K}$

Matthews, Manyalibo J., 02, 06, 14

Meadows, Alexander R., 00

Melninkaitis, Andrius, $1 \mathrm{~W}$

Mende, Mathias, 1B

Menoni, C. S., 22

Menor, Marlon G., $0 \mathrm{H}$ 
Michler, Markus, 1L

Minissale, Marco, 1Q

Mirkarimi, P., 22

Mocek, Tomas, 0T

Momgaudis, Balys, 1W

Monneret, Serge, 07, 17

Morgner, U., $1 \mathrm{Z}$

Mühlig, Ch., 1N

Muresan, Mihai-George, 0T

Natoli, Jean-Yves, 13, 1X

Neacsu, Catalin, 0D

Néauport, Jérôme, 05, 17, 1F

Negres, Raluca A., 02, 0E, 14

Norton, M., 02

Nürnberg, F., OF

Oliver, J. B., 1Y

Ollé, A., 17

Olson, Tammy Y., $0 \mathrm{H}$

Oudard, Jean Francois, 0A

Papernov, S., 1Y

Peng, Xiaocong, 1T

Perram, Glen, OS

Pfiffer, Mathilde, 05, 1F

Piris, J., $1 \mathrm{~K}$

Porter, J., 0Z

Potter, Matthew G., 04

Poutous, Menelaos K., 04

Qiu, S. R., 02

Raman, R. N., 02, 06

Rambo, Patrick K., 0Z, 25

Reagan, B. A., 22

Riede, Wolfgang, 08, 1K

Rigatti, A., 1Y

Rinner, Stefan J., 1L

Ristau, Detlev, 0C, 1B, 1C, 1Z, 21

Rocca, J. J., 22

Roehling, J., 22

Rollmann, K., OF

Rostohar, Daniela, 0T

Route, R. R., 22

Rubenchik, Alexander M., 02, 14

Rullier, J.L., 13

Rus, Bedrǐch, $0 \mathrm{O}$

Samanta, Amit, $\mathrm{OH}$

Sanghera, Jasbinder S., 04

Sapkota, Gopal, 04

Sato, Shunsuke A., 1A

Scherrer, Ueli, 1L

Schlichting, S., $1 Z$

Schollmeier, M., $0 Z$

Schroeder, H., 1K

Schwarz, J., 0Z

Sebek, Matej, OT

Shao, Jianda, 0M, 1T

Shaw, L. Brandon, 04

Shea, Kevin, $0 \mathrm{E}$

Shen, N., 02

Shores, J., $0 Z$

Škoda, Václav, 24

Smalakys, Linas, $1 \mathrm{~W}$

Smith, C., 1Y

Smith, Ian C., 0Z, 25

Sozet, M., 17

Speas, C., OZ

Stanion, Ken, 14
Stolz, Christopher J., 0E, 22

Talisa, Noah, 0D, 1U

Tang, Yongjian, 09

Taylor, B., 1Y

Tempea, Gabriel, 0D

Thibault, Dominique, 08

Vanda, Jan, 0T, 24

VanKerkhove, Steven, 0A

Velpula, Praveen K., $0 \mathrm{O}$

Vetsch, Bernhard, 1L

Wagner, Frank R., $1 \mathrm{X}$

Wang, H., 22

Wang, Jue, 0A

Wang, Wenyi, $1 \mathrm{H}$

Wang, Yueliang, 1T

Wang, Zhanshan, 09

Werner, Kevin, $1 \mathrm{U}$

Wernham, Denny, 08, 1K

Willemsen, Thomas, 0C, 1B, 1Z

Wurz, Marc Christopher, 21

Xie, Xudong, $1 \mathrm{H}$

Yabana, Kazuhiro, 1A

Yoo, Jae-Hyuck, 0H, 14

Yuan, Xiaodong, $1 \mathrm{H}$

Zhang, Jinlong, 09

Zhao, Yuanan, 0M, 1T

Zhu, Meiping, 0M, 1T

Ziolek, Carsten, 1I

$\mathrm{Zu}$, Xiaotao, $1 \mathrm{H}$ 


\title{
Conference Committee
}

\author{
Conference Chairs
}

Gregory J. Exarhos, Pacific Northwest National Laboratory

(United States)

Vitaly E. Gruzdev, University of Missouri (United States)

Joseph A. Menapace, Lawrence Livermore National Laboratory

(United States)

Detlev Ristau, Laser Zentrum Hannover e.V. (Germany)

MJ Soileau, University of Central Florida (United States)

\section{Conference Program Committee}

Detlev Ristau, Laser Zentrum Hannover e.V. (Committee Chair) (Germany)

James E. Andrew, AWE plc (United Kingdom)

Jonathan W. Arenberg, Northrop Grumman Aerospace Systems (United States)

Mireille Commandré, Institut Fresnel (France)

Stavros G. Demos, University of Rochester (United States)

Leonid B. Glebov, CREOL, The College of Optics and Photonics, University of Central Florida (United States)

Takahisa Jitsuno, Osaka University (Japan)

Klaus Mann, Laser-Laboratorium Göttingen e.V. (Germany)

Carmen S. Menoni, Colorado State University (United States)

Masataka Murahara, Tokai University (Japan)

Jérôme Néauport, Commissariat à l'Énergie Atomique (France)

Semyon Papernov, University of Rochester (United States)

Wolfgang Rudolph, The University of New Mexico (United States)

Jianda Shao, Shanghai Institute of Optics and Fine Mechanics (China)

Michelle D. Shinn, Thomas Jefferson National Accelerator Facility (United States)

Christopher J. Stolz, Lawrence Livermore National Laboratory

(United States) 
Proc. of SPIE Vol. 10014 1001401-10 Downloaded From: https://www.spiedigitallibrary.org/conference-proceedings-of-spie on 26 Apr 2023
Terms of Use: https://www.spiedigitallibrary.org/terms-of-use 


\title{
Symposium Welcome
}

\author{
Joseph Menapace \\ Lawrence Livermore National Laboratory, USA
}

On behalf of co-chairs of this meeting, Gregory Exarhos, Vitaly Gruzdev, Detlev Ristau, and M. J. Soileau, I extend a hearty welcome to all participants of the Annual Laser Damage Symposium - the Forty Eighth Annual Symposium on Optical Materials for High-Power Lasers. Following a long-term tradition, this meeting is held in Boulder, Colorado, but this year its participants enjoyed a new venue - the Millennium Harvest House Hotel. This Symposium was founded by Art Guenther and Alex Glass in 1969 to bring together researchers in the young laser community to quickly resolve a specific problem: why and how laser radiation damages materials that are assumed to be highly transparent. The "specific problem" turned out to be very non-trivial and quickly drove researchers to recognize the need to join the efforts of scientists from optics, solid-state physics, materials science, chemistry, and other areas. The deeper the problem was investigated, the more aspects of the problem were brought to attention of laser researchers and engineers. Within few years of the first meeting in 1969, this conference became a major international platform for lively discussions and communication between researchers and engineers from academics, industry, and military related to all aspects of laser-induced damage. The stable number of presentations indicates the enormous vitality of this problem. Among the motivations of research in this field are the continuous extension of the range of laser parameters towards shorter pulses, shorter wavelengths, and higher powers; development of novel lasers; novel optical materials; and operation of traditional lasers under new environments. Ultrafast laser systems have also enabled development of novel techniques and methods for characterization of transient response of optical materials to high-power laser action. Rapid progress in material science has resulted in development of new types of optical materials with a high potential of applications in high-power laser systems. Those and many other developments in the field of high-power/ high-energy lasers continuously support interest in the field of laser damage.

In view of that continuous progress, it is important to track the previous research. The Proceedings of the Boulder Damage Symposium (BDS) have become the most complete and major resource of information on laser damage and related areas compiled from the early stages of that field onwards. The 40-year collection of the Proceedings (from 1969 to 2008 inclusive) published by SPIE on a single DVD was recently supplemented by another DVD with a collection of Proceedings papers from 2009 through 2014. The tremendous efforts of the authors to prepare manuscripts for this series of the Proceedings of SPIE help to maintain the unique status of the Proceedings and are gratefully acknowledged here. In addition to the Proceedings, a Special Section on Laser Damage was published in Optical Engineering - a major SPIE journal - in December 2012, December 2014, and January 2017.

Significant contributions to the success of the BDS have been made by the International Program Committee (IPC) representing leading research centres and groups of the laser-damage community worldwide. Presently, the IPC consists of representatives from the United States of America, Germany, France, Japan, China and the UK. Besides providing contributions to the conference programme, the IPC also promotes the conference and attracts researchers from around the world. The engagement of the Committee that initiated participation from more than 30 countries during the last decade is acknowledged as being highly important. Tremendous efforts of the IPC Chair - Dr. Detlev Ristau of Laser Zentrum Hannover (Germany) - to keep IPC actively working are acknowledged.

Following a 48-year tradition, the conference addresses four core topics including Materials and Measurements, Fundamental Mechanisms, Thin Films as well as Surfaces, Mirrors and Contamination. One keynote presentation is delivered for each of the topics to give an overview of a specific research area and to educate the younger generation of the conference participants. In order to track the current trends in research and further intensify scientific dialogue at this meeting, a mini-symposium dedicated to a current hot topic in laser material interaction was organised and has been every year since 1992. This year's mini-symposium, "Overview of Large-Scale, High-Power Laser Facility Projects" was chaired by Dr. Stefan Borneis, GSI, Germany and Dr. Christopher Stolz, Lawrence Livermore National Laboratory, USA. The outstanding efforts of Stefan in preparation of this year's Mini-Symposium and his dedication to this field of research are especially acknowledged here.

Continuing the success of the damage competition held for the first time in 2008, Chris Stolz and Raluca Negres (both of Lawrence Livermore National Laboratory, USA) have kindly organized another competition that continues 
the efforts of the previous year focused on multilayer coatings for broadband low-dispersion mirrors for high-power femtosecond lasers. In contrast to 2015, this year's competition considers 45 degree angles of incidence with ppolarized light. Samples were submitted by companies and research institutes from China, Japan, Germany, and the United States. As in 2015, Femto-Solid Dynamics Laboratory of the Ohio State University accomplished an enormous amount by evaluating the laser-induced damage threshold of all samples. Efforts of the laboratory team lead by Dr. Enam Chowdhury are greatly acknowledged here. This outstanding effort is appreciated by the laserdamage, optical-coating, and high-power-laser communities and this special contribution by Raluca Negres and Chris Stolz are also acknowledged here. Raluca delivered a talk about the competition and has prepared a summary paper that can be found in this volume of the conference proceedings.

One of the youngest traditions of the symposium is to acknowledge authors who presented significant and notable results at the previous year's meeting. This year, the authors received Best Presentation awards consisting of a monetary prize in the amount of $\$ 50$, and a cut-glass piece of art with the symposium emblem and date and names of the authors embedded into the glass by controlled laser-induced damage made with focused beam from a Qswitched laser. Eligibility for this award includes outstanding scientific content in a presentation, brilliant presentation style, and publishing manuscripts of nominated presentations in the conference proceedings.

Two more remarkable events from this year's meeting are the round-table Standardization Discussion organized by Detlev Ristau and the tutorial on advanced materials for high laser-damage resistance conducted by Marco Jupe (Laser Zentrum Hannover, Germany). The efforts of Detlev and Marco are gratefully acknowledged.

Much of the success of the meeting can be attributed to the untiring efforts of the SPIE conference staff and Bobbie Williams of Lawrence Livermore National Lab (Symposium Assistant). We gratefully appreciate the annual cosponsoring by the Lawrence Livermore Laboratory which significantly supported this meeting. The contributions of the Femto-Solid Dynamics Laboratory of the Ohio State University who performed the laser damage tests for the annual laser-damage thin-film competition is greatly appreciated. We also appreciate support from the Pacific Northwest National Laboratory and Office of Naval Research. We also acknowledge the other cooperating organizations: School of Optics - CREOL and FPCE, College of Optics and Photonics, University of Central Florida; and University of Missouri. We also acknowledge the support of our sponsors this year: Alpine Research Optics, Quantel Laser, Arrow Thin Films, REO, KM Labs, Spica Technologies Inc., Laser Components, LIDARIS, ZC Optoelectronic Technologies LTD.

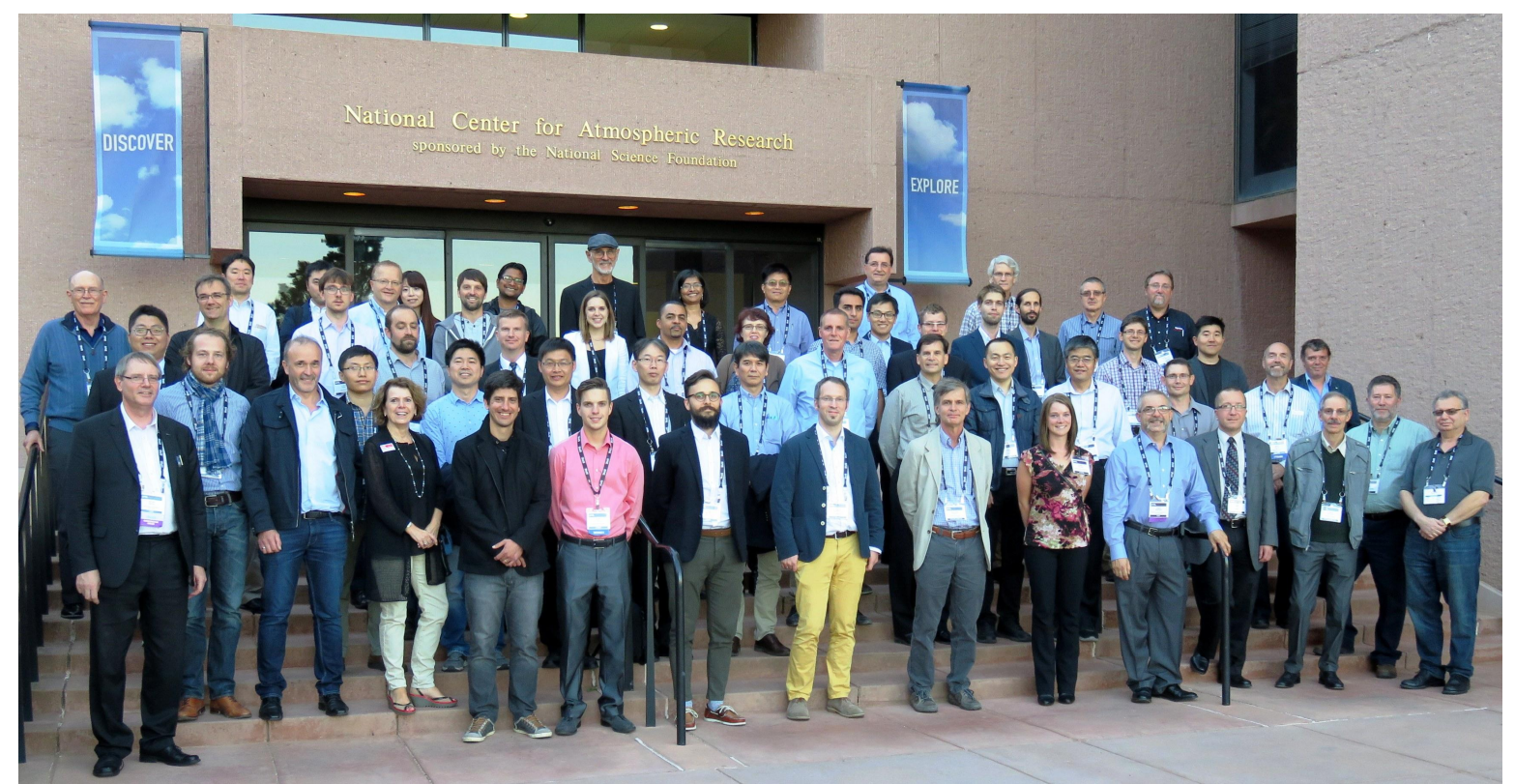

Participants of the $48^{\text {th }}$ Laser Damage Symposium at the entrance to the National Institute of Atmospheric Research in Boulder, CO on Tuesday, September 27, 2016.

Institute of Atmospheric Research in Boulder, CO. 


\title{
Summary of Meeting
}

\author{
SPIE Laser Damage Symposium \\ $48^{\text {th }}$ Annual Symposium on Optical Materials for High Power Laser \\ 25-28 September 2016
}

\author{
Vitaly E. Gruzdev \\ Department of Mechanical and Aerospace Engineering \\ University of Missouri \\ Columbia, MO, 65211, USA
}

\begin{abstract}
1. Abstract
These proceedings contain the papers presented as oral and poster presentations at the $48^{\text {th }}$ SPIE Laser Damage Symposium (aka Annual Symposium on Optical Materials for High-Power Lasers). The conference was held at the Millennium Harvest House Hotel in Boulder, Colorado on 25-28 September 2016. The symposium was divided into oral and poster sessions following the traditional four major topics: thin films; surfaces, mirrors and contamination; fundamental mechanisms; materials and measurements. A mini-symposium was held this year as an overview of largescale high-power laser facility projects. A tutorial on advanced materials for high laser-damage thresholds was held as a special pre-symposium event on Sunday evening, September 25. The conference was opened by Dr. Joseph A. Menapace with a symposium welcome. Dr. Gregory J. Exarhos of Pacific Northwest National Laboratory (USA), Dr. Vitaly Gruzdev of the University of Missouri, Columbia (USA), Dr. Joseph A. Menapace of the Lawrence Livermore National Laboratory (USA), Dr. Detlev Ristau of the Laser Zentrum Hannover e.V. (Germany), Dr. M. J. Soileau, of the University of Central Florida (USA) co-chaired the symposium. The founding organizers of the symposium are Dr. Arthur H. Guenther and Dr. Alexander J. Glass.
\end{abstract}

82 abstracts were submitted to the symposium, of which 70 were presented at 12 oral sessions and 4 poster sessions. No parallel sessions were held allowing the opportunity to discuss common research interests with all the presenters. With 128 attendees 69 of which were authors and meeting co-chairs, the meeting offered an outstanding opportunity to make many new acquaintances. Although held annually in the US, the Laser Damage symposium continues to be a truly international conference with $67 \%$ of the presentations and $47 \%$ of attendees coming from Europe and Asia this year. Following much feedback from symposium participants, the Symposium was relocated from the National Institute of Standards and Technology to Boulder Millennium Harvest House Hotel in Boulder, Colorado which offered a setting conductive to effective communication and interchange between Symposium participants.

In May 2016, a cross promotion relationship was established with the High Power Laser Ablation international conference (HPLA) held bi-annually in Santa Fe, New Mexico, USA. We consider this a first step in establishing a supportive collaboration between the two conferences and the two communities (i. .e, laser damage and laser ablation) with the scopes significantly overlapping many topics.

The 49th Annual Symposium of this series will be held in Boulder, Colorado, 24-27 September 2017:

http://spie.org/LD/conferencedetails/laser-damage-boulder

A continuous effort will be made to ensure a close liaison between the high-energy, high-peak-power, and high-averagepower laser communities, as well as to include damage issues related to various research efforts and commercial laser applications. A mini-symposium will be focused on giving an overview of recent progress in the field of ultrafast science. Several top experts are anticipated to deliver invited talks for the mini-symposium and four major topical areas of the conference.

The principal topics to be considered in 2017 do not differ drastically from those enumerated above. We expect to hear more about the impacts of environment, aging, contamination on the laser resistance of optical components, and the influence of defects since those topics continue to generate significant interest. High-energy laser windows, crystals, and transparent ceramics continue to place limitations on laser systems so remain an active area of research and spirited debate. Refinement of the mitigation strategy consisting of damage initiation followed by arresting damage growth through post-processing techniques while not creating downstream damage is also expected to be a continued focus as a 
large number of laser-resistant UV optics are manufactured for laser-lithography applications. Short pulse (nanosecond and picosecond) laser optics and damage phenomena remain an active area of research. Recent progress in the fields of ultrashort-pulse (femtosecond) lasers and ultrafast laser-material interactions is believed to be a growing area for future symposiums. We also expect to hear more about new measurement techniques to improve our understanding of the different damage mechanisms or to improve the manufacturing of optical materials and thin films for optical components of greater laser damage resistance. Thin films for a broad range of laser wavelengths and pulse durations will continue to stay one of hot topics of the symposium. Also, new developments in the field of meta-materials and related laser-damage issues will attract growing attention due to their intensive development and potential use in highpower lasers. Fundamental aspects of laser-induced damage including multiphoton and avalanche ionization, scaling of damage threshold with laser and material parameters continuously attract a lot of attention especially for the case of ultrashort-pulse laser damage. More presentations on the fundamental effects of ultrafast laser-matter interactions with are expected in 2017 due to the recent progress of ultrafast science and breakthrough research in that field.

As was initially established in 1992, several distinguished invited speakers will deliver keynote presentations of a tutorial or review nature, in addition, other invited contributors will cover recent breaking developments. Another tutorial on laser damage by ultrashort laser pulses is expected to be delivered as a pre-symposium event on Sunday. A special event of this conference was a Standardization Round-Table Discussion held on Monday, September 26.

The purpose of this series of symposia is to provide an international platform for information exchange about optical materials for high-power / high-energy lasers, fundamental mechanisms of laser-solid interactions, and a broad range of topics related to laser-induced damage in those materials. The editors welcome comments and criticism from all interested readers relevant to this purpose.

Key words: laser damage, laser-material interaction, high-power lasers, high-energy lasers, optical components, optical fabrication, optical materials, thin film coatings, contamination, ultrafast laser-matter interactions.

\section{Introduction}

The SPIE Laser Damage Symposium - 48 th Annual Symposium on Optical Materials for High-Power Lasers (a.k.a. the Boulder Damage Symposium, because of its Boulder, Colorado, venue) was held 25-28 September 2016. This symposium continues to be the principal US and International forum for the exchange of information relative to laserinduced damage in optical materials and the interaction of intense laser light with optical media and components. This year, it was attended by 128 representatives of academia, industry, national research laboratories and centers from 11 countries that was about 5\% increase in attendance compared to Laser Damage-2015 (Fig. 2). 82 abstracts were submitted to the Symposium, 80 of them were included into the final program, and 70 were delivered within the traditional 3-day format of the meeting including 42 oral and 28 poster presentations. This year 12 presentations were cancelled or not presented. Although, held annually in the US, this is a truly International conference with $47 \%$ of the attendees and 67\% percent of the presentations coming from abroad this year (Fig. 3). Historically, the meeting has been divided into four broad categories: thin films; fundamental mechanisms; materials and measurements; and surfaces, mirrors, and contamination. Starting from 1992, a mini-symposium is held to highlight hot research topics and areas of active research and special interest in the fields related to high-power/high-energy lasers, laser-induced damage, optical materials, and laser-material interactions. Starting from 2014, the traditional pre-symposium event - a Round-Table discussion held on Sunday evening - was replaced with a tutorial. This year it featured the influence of fundamental material properties on laser-induced damage under the title "Advanced Materials for High Laser-Damage Resistance". The tutorial was prepared and held by Dr. Marco Jupe (Laser Zentrum Hannover, Germany) on Sunday, 25 September. The tutorial attracted more than 70 participants of the conference. The conference began on Monday, 26 September 2016 with a welcome talk delivered by Joseph Manapace (Lawrence Livermore National Laboratory, USA).

\section{Symposium Cochairs}

The Boulder Damage Symposium was founded by Dr. A. H. Guenther and Dr. Alexander Glass. Over the last 48 years many prominent leaders within the high-power laser community have contributed significantly as Co-Chairs to this conference. A historical timeline of their contributions is listed below:

1969 A. H. Guenther, and A. J. Glass (C. M. Stickley)

1979 add H. E. Bennett and B. E. Newnam

1981 add D. Milam; A. J. Glass departs

1987 add M. J. Soileau 


$\begin{array}{ll}1988 & \text { D. Milam departs } \\ 1989 & \text { add L. L. Chase } \\ 1994 & \text { add M. R. Kozlowski; L. L. Chase departs } \\ 1997 & \text { add G. J. Exarhos and K. L. Lewis; H. E. Bennett and B. E. Newnam depart } \\ 2001 & \text { add C. J. Stolz } \\ 2002 & \text { add N. Kaiser; M. R. Kozlowski departs } \\ 2004 & \text { N. Kaiser departs } \\ 2005 & \text { add D. Ristau } \\ 2007 & \text { A. H. Guenther deceased } \\ 2008 & \text { K. L. Lewis departs } \\ 2009 & \text { add V. Gruzdev } \\ 2010 & \text { add J. A. Menapace; C. J. Stolz departs }\end{array}$

\section{Pre-symposium event: tutorial}

Symposium Tutorial is the newest Symposium event introduced for the first time in 2014. That year, the tutorial was focused on the basics of thin films under the topic "Fundamentals of Growth and Characterization of Amorphous Thin Films for Interference Coatings" and was held by Dr. Carmen Menoni (Colorado State University, USA) and Dr. Wolfgang Rudolph (University of New Mexico, USA). In 2015, the Tutorial was held again as pre-symposium event on Sunday evening. It was prepared and held by Dr. Laurent Gallais (Institut Fresnel, France) and featured defect-induced laser damage under the topic "Defect-Induced Damage in Nano- and Femtosecond Regime". In 2016, the tutorial entitled "Advanced Materials for High Laser-Damage Resistance" was prepared and delivered by Dr. Marco Jupe (Laser Zentrum Hannover, Germany). The lecture part was focused on the interplay of three major topics of this Symposium: optical materials, thin films for optical coatings, and fundamental mechanisms of ultrafast laser-material interactions. Overall, this tutorial addressed the influence of fundamental material properties on laser-induced damage. Correspondingly, the properties of different coating materials and the application of mixture and structuring as well as the coating stack design were discussed from the viewpoint of their effects on laser damage threshold. One of major objectives was to analyze the interplay between material properties and laser-driven electronic processes. At the beginning, the tutorial attracted about 70 participants of the conference, but more people joined it soon after finishing the registration. Total attendance was estimated at the level of 80 people.

Each previous year, attendees of the tutorial were asked for feedback. In 2014, 22 participants responded to a short questionnaire that contained 3 questions about the tutorial. In 2015, organizers received 50 responses. Distribution of the responses is summarized in Table 1 and Figure 1. Participants expressed high level of satisfaction with the Tutorial in 2014 and 2015 that motivated organizers to continue this novel tradition and prepare one more tutorial in 2016 and another one in 2017. Following the topics suggested by the participants of the survey, the tutorial to be delivered in 2017 will focus on mechanisms of laser-induced damage by femtosecond high-power lasers.

Table 1. Summary of a survey of tutorial participants: 2014 vs 2015.

\begin{tabular}{|c|c|c|c|c|c|}
\hline Questions & $\begin{array}{l}\text { Very much / } \\
\text { Surely yes }\end{array}$ & $\begin{array}{l}\text { Rather interesting } \\
\text { / useful }\end{array}$ & $\begin{array}{l}\text { Nothit } \\
\text { / usef }\end{array}$ & $\begin{array}{l}\text { interesting } \\
\text { Jo }\end{array}$ & $\begin{array}{l}\text { Not certain / } \\
\text { not sure }\end{array}$ \\
\hline $\begin{array}{l}\text { Question 1: How interesting was the } \\
\text { Tutorial for you? }\end{array}$ & $\begin{array}{l}\text { 2014: } 1.82 \% \\
\text { 2015: } 68.00 \%\end{array}$ & $\begin{array}{ll}2014: & 63.64 \% \\
2015: & 32.00 \%\end{array}$ & 2014: & $\begin{array}{l}0.00 \% \\
0.00 \%\end{array}$ & $\begin{array}{l}2014: 4.54 \% \\
2015: 0.00 \%\end{array}$ \\
\hline $\begin{array}{l}\text { Question 2: Was the Tutorial useful and } \\
\text { informative for you? }\end{array}$ & $\begin{array}{ll}\text { 2014: } & 22.73 \% \\
\text { 2015: } & 56.00 \%\end{array}$ & $\begin{array}{l}77.27 \% \\
44.00 \%\end{array}$ & 2014: & $\begin{array}{l}0.00 \% \\
0.00 \%\end{array}$ & $\begin{array}{l}2014: 0.00 \% \\
2015: 0.00 \%\end{array}$ \\
\hline $\begin{array}{l}\text { Question 3: Assuming you attend Laser } \\
\text { Damage-16, would you attend Tutorial? }\end{array}$ & $\begin{array}{l}\text { 2014: } 81.82 \% \\
\text { 2015: } 96.00 \%\end{array}$ & $\begin{array}{l}\mathrm{N} / \mathrm{A} \\
\mathrm{N} / \mathrm{A}\end{array}$ & $\begin{array}{l}\text { 2014: } \\
\text { 2015: }\end{array}$ & $\begin{array}{l}0.00 \% \\
0.00 \%\end{array}$ & $\begin{array}{l}\text { 2014:18.18\% } \\
\text { 2015: } 4.00 \%\end{array}$ \\
\hline
\end{tabular}

\section{Thin Films}

Because of the tremendous range of applications of optical multilayer coatings for modifying the optical performance of elements (e.g., reflectivity, wavelength sensitivity, polarization, or simply protection), this category continues to receive very significant attention. Besides damage thresholds or sensitivity of particular coatings, topics 

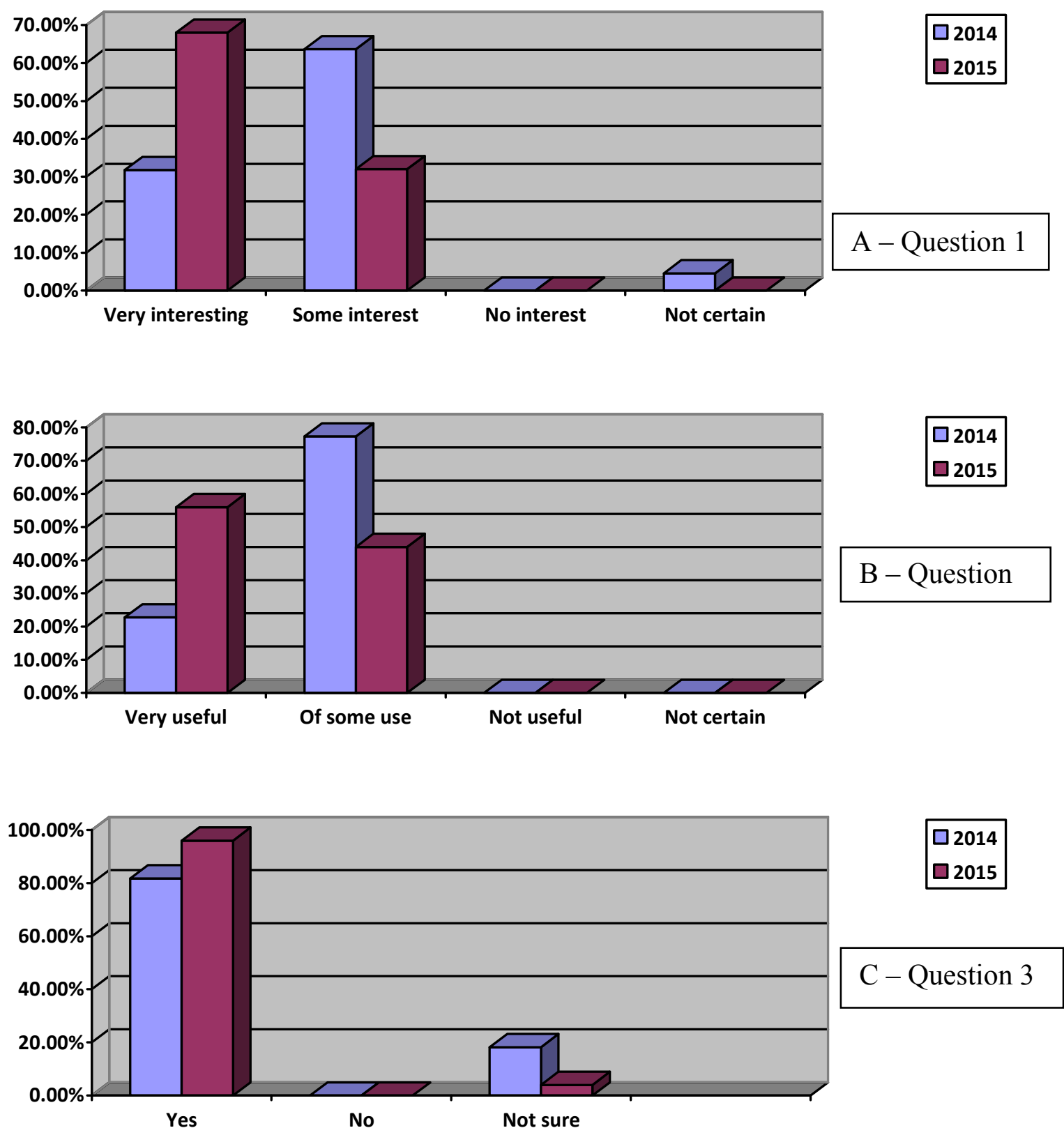

Fig. 1. Graphical representation of responses of tutorial participants to the questions listed in Table 1.

include improvement of manufacturing methods, film structure, film design, novel oxide materials for the films, film response to environmental attack and aging, structural microscopic defects, and numerous reports on important film properties such as absorption and stability. Attention is traditionally paid to coatings at $1064 \mathrm{~nm}, 532 \mathrm{~nm}, 355 \mathrm{~nm}$, and deep-UV (e. g., $193 \mathrm{~nm}$ ), but coatings for IR continue receiving increased attention this year. Remarkable are the talks devoted to improvement of the traditional thin films made of $\mathrm{HfO}_{2} / \mathrm{SiO}_{2}$ materials and deposition of films from $\mathrm{Al}_{2} \mathrm{O}_{3}$ that is not a very popular coating material. Significant attention was paid to preparation of substrate for improved thinfilm quality. Thin-film damage by ultrashort pulses continues to be one of the fields attracting constantly high attention, and this year we heard about laser damage of coatings by few-cycle mid-infrared pulses.

Dense thin films offer the benefit of environmental stability, and a significant research is proceeding in this direction in the field of thin films. Laser interaction studies uncover areas where dense films offer advantages over traditional e-beam 
coatings. Also as shown in the thin film damage competition, there are a number of companies that are manufacturing dense coatings by a variety of deposition techniques delivering very high laser resistance. As before, thin-film laser damage competition is one of major events of Thin Film section of the Symposium.

Coating defects and interfaces continue to be an area of active interest in both process of optimization to minimize defect density and formation as well as mitigation techniques such as laser conditioning. We continue to see interest in defect detection and characterization in films and coatings. This year, invited talk of Dr. Zhanshan Wang (Tongji University, China) emphasized nanosecond laser-induced damage and the role of structural defects of high reflectors in a broad spectral range from near-IR to near UV.

\section{Thin-film laser damage competition}

This year the ninth thin-film damage competition was organized by Dr. Christopher Stolz and Dr. Raluca Negres of Lawrence Livermore National Laboratory (USA). It started in 2008 to sample the industrial, government, and academic sectors producing high laser resistant optical coatings. This year, the competition extended the one from 2016 and considered broadband low-dispersion mirrors for damage testing by 40 -fs laser pulses. The requirements included wavelength range $(773 \pm 50 \mathrm{~nm}$ ), minimum reflection of $99.5 \%$ at 45 degrees angle of incidence, and GDD smaller than $100 \mathrm{fs}^{2}$. No requirements were put on deposition method, coating material and design. Sample filters from several companies and institutes from the USA, Europe, and China were tested at $773 \mathrm{~nm}$ at the laser-damage test facility of Femto-Solid Dynamics Laboratory of Dr. Enam Chowdhury of the Ohio State University (USA). A multitude of deposition processes, coating materials, and manufacturing techniques submitted to this competition provided highly interesting results that will likely lead to some significant future research.

$2008 \quad$ HR mirrors for Nd-YAG lasers, wavelength $1064 \mathrm{~nm}$, nanosecond pulses

$2009 \quad$ HR mirrors for Ti-sapphire lasers, wavelength $780 \mathrm{~nm}$, femtosecond pulses

$2010 \quad$ AR coatings for excimer lasers, wavelength $351 \mathrm{~nm}$, nanosecond pulses

$2011 \quad$ HR mirrors for excimer lasers, wavelength $193 \mathrm{~nm}$, nanosecond pulses

2012 Brewster-angle thin film polarizer, wavelength $1064 \mathrm{~nm}$, nanosecond pulses, p-polarization

2013 Brewster-angle thin film polarizer, wavelength $1064 \mathrm{~nm}$, nanosecond pulses, s-polarization

2014 Narrow-bandwidth Fabry-Perot transmission filters, wavelength 1064, nanosecond pulses

2015 Broadband low-dispersion mirror, wavelength $773 \mathrm{~nm}$, picosecond pulses

2016 Broadband low-dispersion femtosecond mirror, wavelength $773 \mathrm{~nm}, 45$ degrees AOI, p-polarization

\section{Fundamental Mechanisms}

This area deals with the fundamental effects and mechanisms of interactions of light with matter. Topics include laserinduced ionization, nonlinear behavior and effects of material response, self-focusing and other propagation effects, modeling of thermal and non-thermal processes, and experimental data reduction protocols (e.g. effects of pulse width, repetition rate or duty cycle, spot size, wavelength, temperature, ionizing radiation, and other basic environmental effects). Also, of great interest are all types of scaling relationships between laser-induced damage thresholds and material/laser/environment parameters that not only afford insight into the fundamentals of the interaction process, but allow extrapolations for engineering and cost-benefit evaluations. In many areas, these insights are based on real-world, systems-level tests, as opposed to a frequently pristine laboratory environment.

A significant amount of experimental and simulation work is now being done in the femtosecond regime as exemplified by the significant number of submitted papers on ultrafast phenomena. They consider both bulk and surface effects including formation of surface-damage craters. Novel simulation approaches, e. g., first-principle simulations by densityfunctional theory and modified particle-in-cell method have been proposed and demonstrated excellent agreement with experimental data. This year's presentations were mainly focused on ultrafast laser-material interactions including laserinduced ionization, characterization of laser-damage morphology, dual-wavelength and polychromatic effects in laserinduced ionization, the fundamental influence of defects and band structure of optical materials on laser-induced damage threshold and linear vs non-linear absorption. Increasing attempts to expand the traditional ionization models beyond the monochromatic approximation are very remarkable. Continuous efforts are made to characterize the fundamental mechanisms of laser damage in fused silica and KDP/DKDP crystals as the most popular optical materials. The invited talk by Dr. Laurent Lamaignere (CEA, France) featured the fundamental relation between damage mechanisms and damage morphology. 


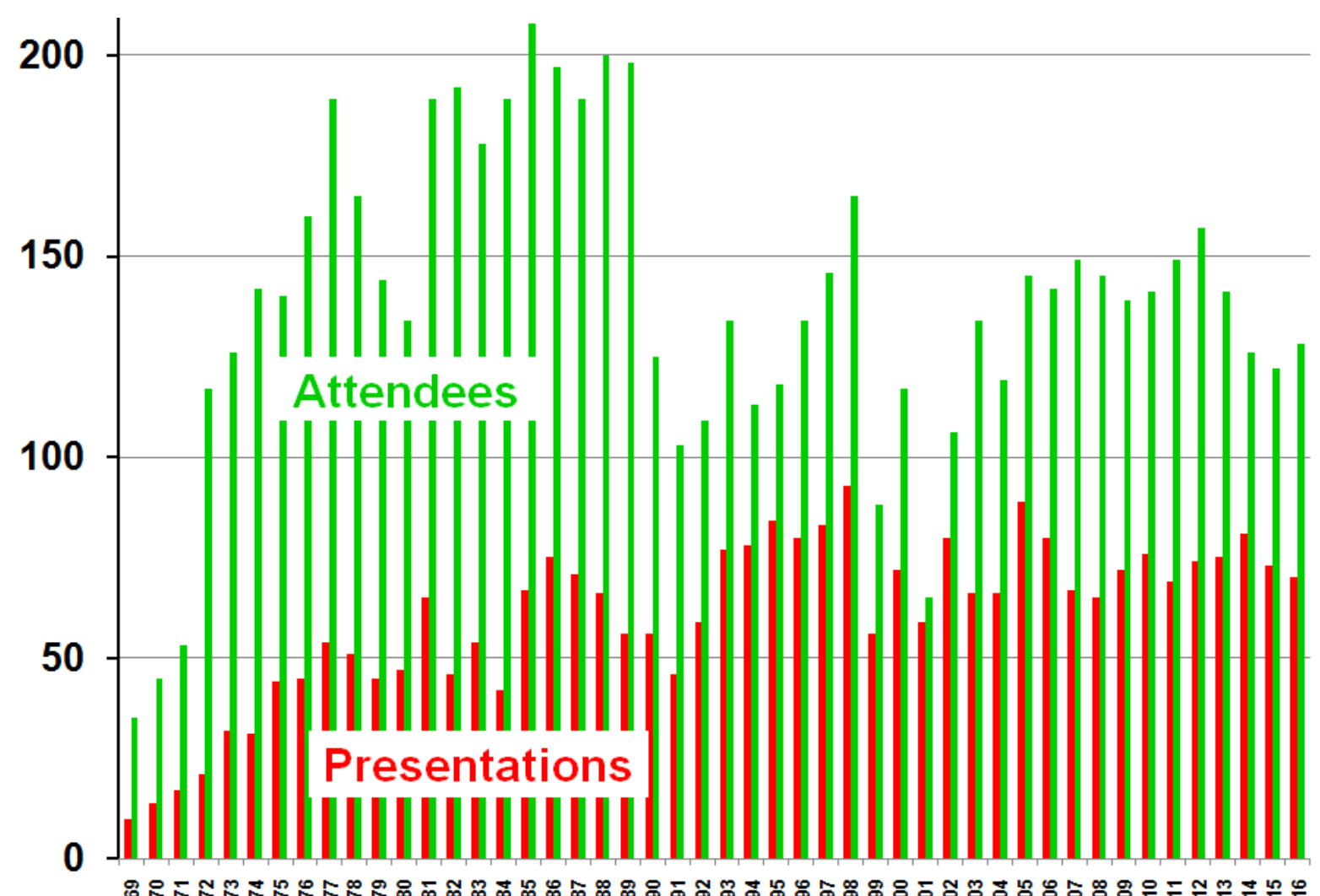

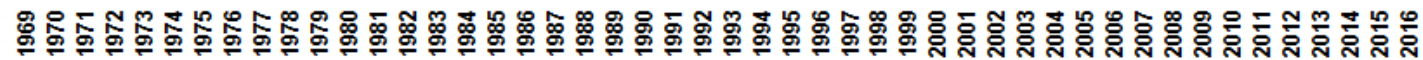

Fig. 2. Registered participants (green lines) vs number of presented papers (red lines) since 1969 till 2016 inclusive.

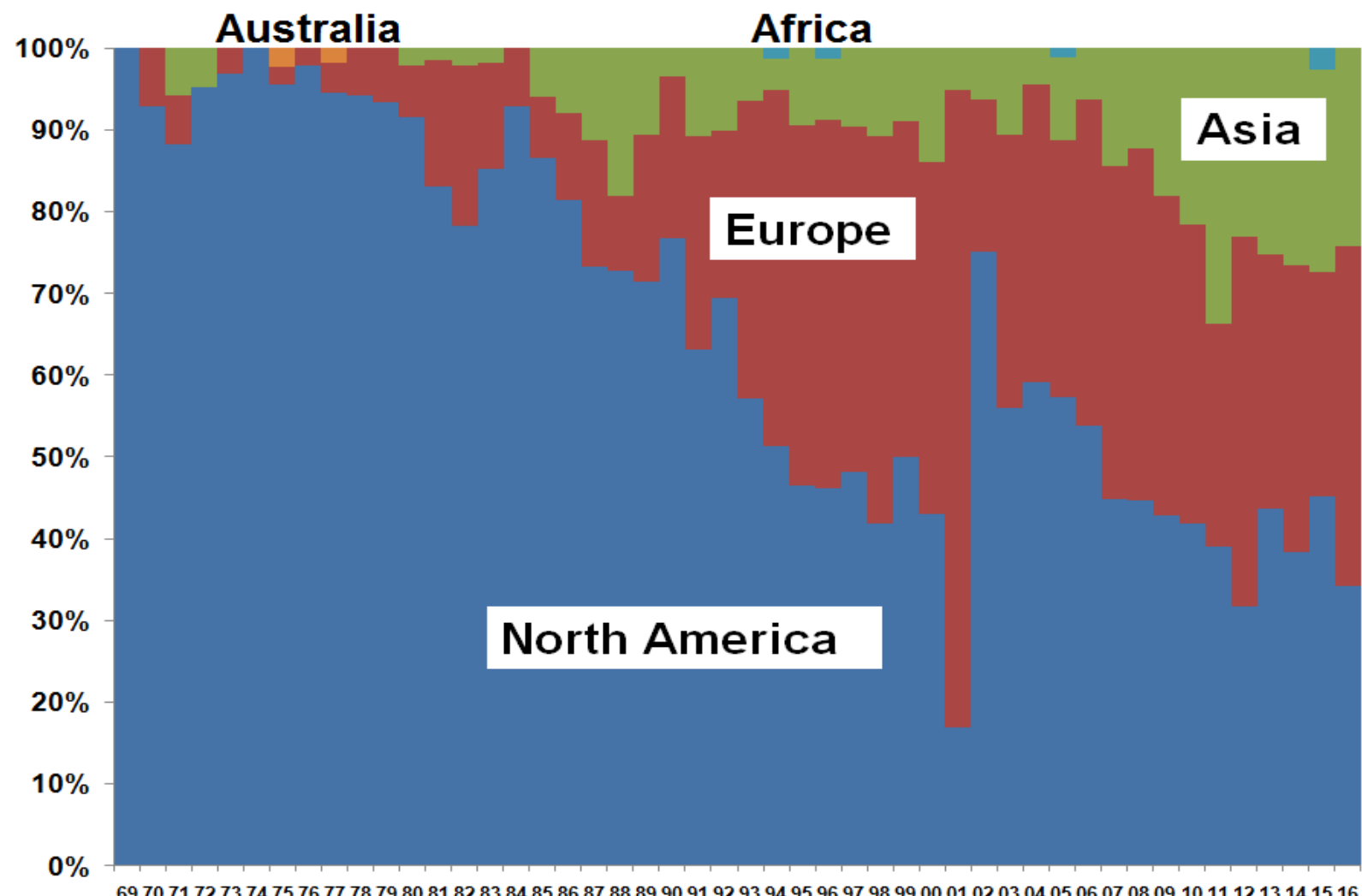

697071727374757677787980818283848586878889909192939495969798990001020304050607080910111213141516

Fig. 3. Distribution of the presentations (both oral and poster) delivered at the conference from 1969 till 2015 inclusive. 


\section{Surfaces and Mirrors}

Presentations of this category are devoted to surface preparation, subsurface damage characterization, roughness and scattering, environmental degradation and aging, as well as substrate material properties, including cooling techniques, and, of course, damage measurement, and cleaning of surfaces. The crux of the contamination problem is fundamentally that damage experiments done in controlled clean laboratory settings do not necessarily yield the same results as laser operations in less pristine operating environments. There is a significant amount of work needed in understanding what contamination is acceptable, what contamination is threatening to optic survivability, and how fluence-limiting or lifetime-limiting contamination can be eliminated or mitigated from operating lasers.

This year, significant number of presentations is devoted to laser-induced contamination by particles deposited on a surface. A fair amount of papers deals with substrate preparation prior to thin-film deposition, laser-damage mitigation, and surface micro- and nano-structuring to enhance surface reflection without depositing any kind of optical coatings. The problem of resistance to laser radiation becomes prevalent for application of those reflection-enhancing nanosctructuring techniques in high-power laser systems. Decontamination and refining of optical surfaces and the impact of contamination on laser resistance still stay the topics of active research and discussion. Significant attention was paid to damage initiation by scratches and to influence of polishing techniques. The invited talk by Dr. Manyalibo Matthews (Lawrence Livermore National Laboratory, USA) featured the mechanisms of laser-surface coupling that govern surface laser-induced damage.

\section{Materials and Measurements}

Among the four main sections of the conference, this one continuously stays the largest over last decade (Figs. 4 and 5). This section deals with protocols and setups (e.g., automated facilities) for measurements of laser damage to the bulk of transparent optical media whether amorphous, polymeric, polycrystalline, or crystalline; reports on material properties of importance for their optical function and/or the damage process, e.g., linear and nonlinear absorption coefficients, thermal conductivity, stress-optic coefficients, moduli, scattering, and various defects. Also included are new techniques for measuring these quantities, which present a continuing challenge as materials are improved in quality and diversity. This year, presentations covered a very broad range of optical materials including fused silica, KDP/DKDP crystals, calcium fluoride, PPMA polymers, metals, and Nd-doped ceramics focusing on characterization of both their properties and damage thresholds.

There is always interest in improved measurement systems or new instruments particularly in the areas of nondestructive characterization and defect detection. Laser damage measurements are difficult, and work continues on developing tests that address large area versus small area and the difficulties of obtaining data with high space resolution. Significant efforts are reported on investigation of damage precursors and initiators, their identification and elimination. Impressing reports are delivered on automated programmable systems for defect identification and blocking for mitigating laser-induced damage. Continuous efforts have been reported on measurement of absorption for deep-UV optics, characterization of nonlinear absorption, and separation of bulk and interface contributions to the total absorption of optics with single or multiple interfaces. Continuous efforts are made to verify and improve ISO standards on laser damage threshold and determine the most effective stochastic approaches to evaluation of laser-damage threshold. The invited talk by Dr. Frank Nuernberg (Heraeus Quarzglas GmbH \& Co., Germany) featured characterization of the fundamental optical properties of fused silica and their relation to hydrogen defects.

\section{Mini-Symposium}

This year the meeting hosted the mini-symposium on Review of Large-Scale, High-Power Laser Facility Projects chaired by Dr. Stefan Borneis of GSI, Germany and Dr. Christopher Stolz of Lawrence Livermore National Lab, USA With 8 invited talks spread over two oral sessions, the mini-symposium truly represented all the currently operating or underconstruction large-scale laser facilities worldwide. Presented were the ELI Beamlines Facility (European Union), SG-III laser Facility (China), LMJ: PETAL project (France), Z-Backlighter Laser Facility (Sandia National Lab, USA), ILE/Osaka University Lasege-Scale Laser Facility (Japan), Orion Laser Facility (Unived Kingdom), and LIGO Laser Facility (USA). This event became one of the brightest events of this conference. The Mini-Symposium of Laser Damage 2017 will be devoted to the frontiers of research in ultrafast laser-matter interactions and ultrafast science. IT will be chaired by Vitaly Gruzdev.

A brief summary of the past mini-symposium topics staring from 1992 and the organizing chairs is listed below. 


\begin{tabular}{|c|c|c|}
\hline Year & Chair & Topic \\
\hline 1992 & Brian Newnam & Damage Issues for Lithographic Optics \\
\hline 1993 & Karl Guenther & $\begin{array}{l}\text { Quest for the Invincible Laser Coating - Critical Review of Pulse Laser-Induced } \\
\text { Damage to Optical Coatings: Causes and Cures }\end{array}$ \\
\hline 1994 & Claude Klein & Diamond for Optics Applications in Adverse Environment \\
\hline 1995 & Floyd Hovis & Contamination and the Laser Damage Process \\
\hline 1996 & Robert Setchell & Laser-Induced Damage in Optical fibers \\
\hline 1997 & David Welch & Damage and Lifetime Issues for Laser diodes \\
\hline 1998 & Norbert Kaiser & Optics for Deep UV \\
\hline 1999 & David Sliney & Laser Damage Processes in the Eye and Other Biological Tissue \\
\hline 2000 & $\begin{array}{l}\text { Mark Kozlowski } \\
\text { Hideo Hosono }\end{array}$ & Defects in Glass \\
\hline 2001 & Mark Kozlowski & Optical Materials for Telecommunications \\
\hline 2002 & Detlev Ristau & $\begin{array}{l}\text { Optics characterization }- \text { joint with } 7^{\text {th }} \text { International Workshop of Laser Beam } \\
\text { and Optics characterization }\end{array}$ \\
\hline 2003 & William Latham & Understanding Optical Damage with Ultra-short Laser Pulses \\
\hline 2004 & Keith Lewis & Damage Issues in Fiber Laser systems \\
\hline 2005 & Leon Glebov & Petawatt Lasers \\
\hline 2006 & Alan Stewart & Optics in a Hostile Environment \\
\hline 2007 & Stan Peplinski & Lifetime Issues for CW and Quasi-CW Lasers \\
\hline 2008 & $\begin{array}{l}\text { Christopher Stolz } \\
\text { Herve Bercegol }\end{array}$ & Fused Silica \\
\hline 2009 & Wolfgang Rudolph & Femtosecond Laser-Induced Damage \\
\hline 2010 & $\begin{array}{l}\text { Klaus } \\
\text { Sokolowski-Tinten }\end{array}$ & Fundamentals of Laser Ablation \\
\hline 2011 & $\begin{array}{l}\text { Holger Blashke, } \\
\text { Carmen Menoni }\end{array}$ & Deep-UV Optics \\
\hline 2011 & Michelle Shin & Meta-Optics/Photonic Band Gap Materials \\
\hline 2012 & Stavros Demos & Laser-Induced Plasma Interactions \\
\hline 2013 & Leonid Glebov & High-Power Fiber Lasers \\
\hline 2014 & Stavros Demos & Applications Related to Laser Damage \\
\hline 2015 & Vladimir PErvak & Laser-Induced Damage to Multilayers in Femtosecond Regime \\
\hline 2016 & $\begin{array}{l}\text { Stefan H. Borneis } \\
\text { Christopher J. Stolz }\end{array}$ & Review of Large-Scale, High-Power Laser Facility Projects \\
\hline
\end{tabular}

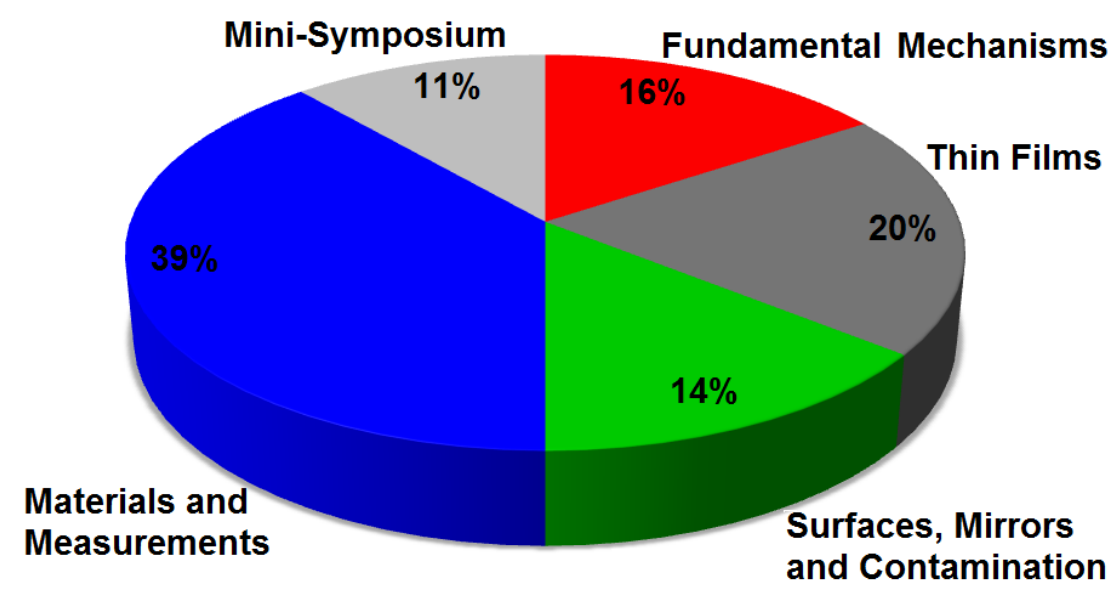

Fig. 4. Distribution of presentations of Laser Damage - 2016 by topics. 


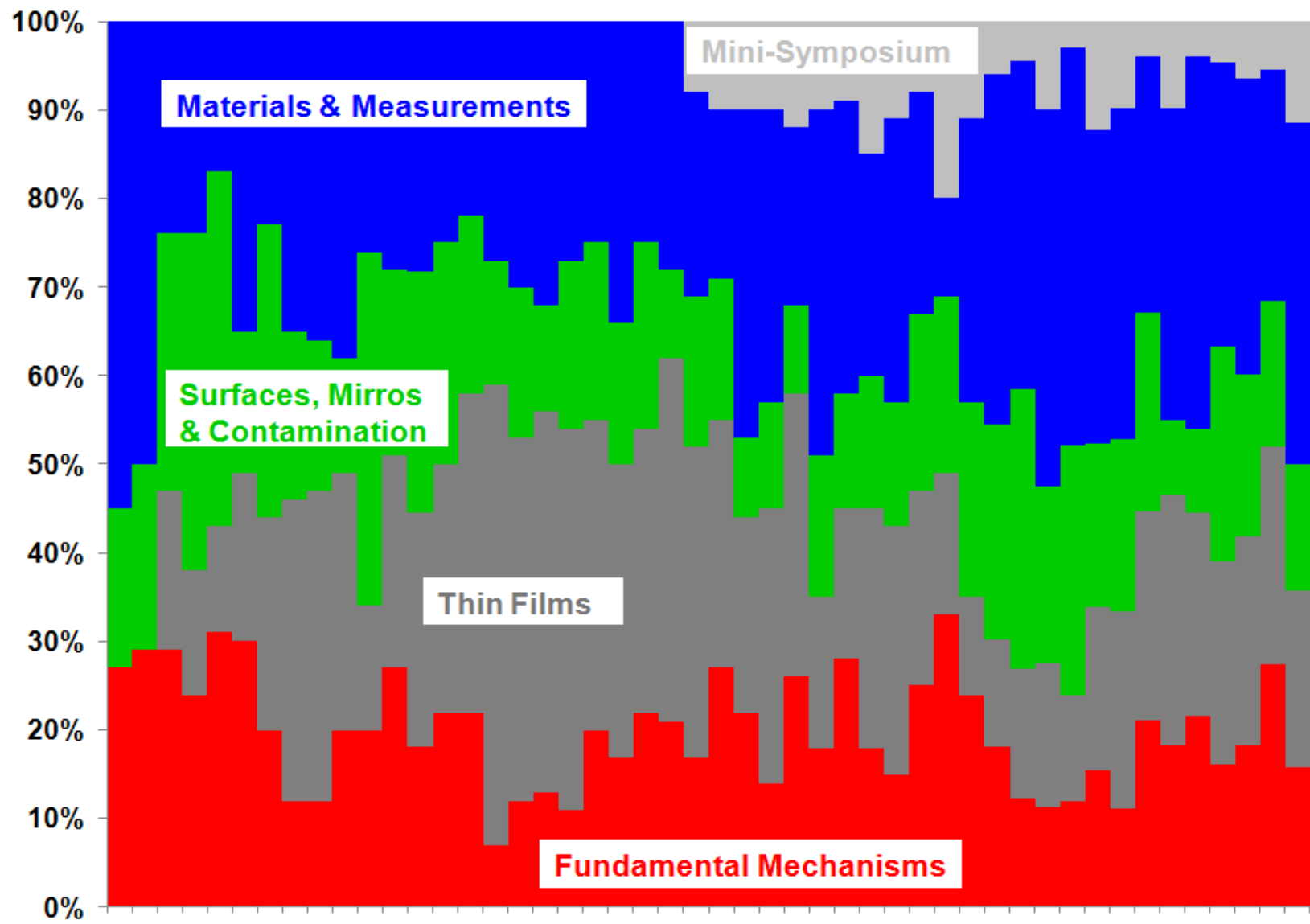

697071727374757677787980818283848586878889909192939495969798990001020304050607080910111213141516

Fig. 5. Distribution of presentations over four major topics and mini-symposium since 1969 through 2015 inclusive.

\section{Keynote and Invited Presentations}

As usually, the $48^{\text {th }}$ Laser Damage Symposium is highlighted by four keynote presentations in the major areas:

1. "Nanosecond laser-induced damage of high-reflection coatings: NUV through NIR", Zhanshan Wang, Jinlong Zhang, Pengfei He, Bin Ma, Hongfei Jiao, Xinbin Cheng, Tongji University (China) - area of Thin Films.

2. "Laser-matter coupling mechanisms governing particulate-induced damage on optical surfaces", Manyalibo J. Matthews, Eyal Feigenbaum, Stavros Demos, Rajesh Raman, Roger Qiu, Nan Shen, Candace Harris, Raluca Negres, Mary Norton, David Cross, Christopher Carr, Jeffrey Bude, Alexander Rubenchik, Lawrence Livermore National Laboratory (USA) - the area of Surfaces, Mirrors, and Contamination.

3. "Investigation of mechanisms leading to laser damage morphology", Laurent Lamaignere, Maxime Chambonneau, Romain Diaz, Pierre Grua, Roger Courchinoux, CEA (France); Jean-Yves Natoli, Institut Fresnel (France); JeanLuc Rullier, CEA (France) - the area of Fundamental Mechanisms.

4. "Metrology of fused silica", Frank Nuernberg, Bodo Kuehn, Klaus Rollmann, Heraeus Quarzglas GmbH \& Co. KG (Germany - the area of Materials and Measurements.

Also, the Mini-Symposium hosted 8 invited talks this year:

1) "ELI-Beamlines and its ultrahigh intensity beam transport system", Stefan H. Borneis, Institute of Physics of the ASCR, v.v.i (Czech Republic) and Gesellschaft fur Schwerionenforschung GmbH (Germany) et al.

2) "Laser performance of the SG-III Laser Facility", Wanguo Zheng, China Academy of Engineering Physics (China) and Shanghai Jiao Tong University (China), et. al. 
3) “Overview of the LMJ:PETAL project", Jerome Neauport, Commissariat a l'Energie Atomique (France).

4) "Challenges offor robust laser systems of ELI-Beamlines", Daniel Kramer, Institute of Physics of the ASCR, v.v.i (Czech Republic).

5) “Sandia’s Z-Backlighter Laser Facility”, Patrick Rambo, Sandia National Laboratory (USA).

6) "Overview of large-scale laser as ILE/Osaks University and future plan", Junji Kawanaka, Osaka University, Japan.

7) "Overview of the Orion Laser Facility: update on performance, experimental schedule, and laser operations", Rory Penman, AWE plc (United Kingdom).

8) "Making a precision measurement at metawatt circulation power levels", Stefan Ballmer, Massashusetts Institute of Technology (USA) and LIGO Science Collaboration (USA).

\section{Conference Awards}

Beginning with the meeting in 2000, the organizers instituted a best paper award in the oral and poster categories. The awards appropriately take the form of laser-induced art in an optical glass plaque. (see, e.g., paper by I. N. Trotski, Proc. SPIE 4679, 392-399 (2001)).

There were several outstanding posters and oral papers, however, the following papers were selected for 2016:

Best oral paper:

Few-cycle pulse laser-induced damage of thin films in air and vacuum ambience, Kyle R. P. Kafka, Noah Talisa, Drake R. Austin, Kevin Werner, The Ohio State University (USA), Gabriel Tempea, Catalin Neascu, Spectra-Physics (Austria), Enam A. Chowdhury, The Ohio State University (USA) [10014-14].

Best poster paper:

Characterization of NLO crystal absorption for wavelengths $1 \omega$ to $4 \omega$, Christian Muehlig, Simon Bublitz, LeibnizInstitut fur Photonische Technologien e. V. [9632-65].

\section{Standardization Round-Table Discussion}

The Standardization Round-Table Discussion was held on Monday, September 2016 from 13:20 through 14:15 during a lunch break between oral sessions. It attracted some 30 participants and was held in the form of a workshop. It was dedicated to recent developments in the field of International Standardization for optics characterization. Specifically, ISO 21245, the International Standard for the measurement of Laser Induced Damage Thresholds, is presently subjected to a major revision within the corresponding Working Group ISO TC 172/SC 9/ WG 1 "Terminology and test methods for electro-optical systems". There was given a brief introduction into the present state of the standard and some other standards of interest elaborated within ISO. It was then followed by a discussion of alterations necessary in the present version of ISO 21254 and their adaptation to the present needs in practical applications and measurements. Further requirements on standardization activities within the laser-damage community were considered and discussed.

\section{Cross promotion with High Power Laser Ablation conference}

In May 2016, a cross-promotion agreement was signed between Laser Damage Symposium (LD) and High Power Laser Ablation international conference (HPLA). HPLA is held each other year (2016 - most recent) in April or May in Santa Fe or Taos, NM. With average number of attendees about 150 and number of presentations varying from 80-100, HPLA is very close to LD (average number of attendees about 125, and number of presentations about 80 ). Very strong international representation (more than $50 \%$ of speakers and attendees from Europe, Asia, and Australia) is characteristic of HPLA. Invited speakers are the top experts of laser-ablation and high-power-laser communities. For example, Prof. G. Mourou - the father of the Chirped-Pulse Amplification method now employed in majority of commercial femtosecond lasers - delivered an invited talk at HPLA meeting in April 2016. Major topics of this conference include:

- FUNDAMENTAL PHYSICS: fundamental physics of laser-material interactions; Theory and simulation of lasermatter interaction; basic mechanisms of laser ablation; ultrafast material modification by femtosecond pulses; ultrafast Xray and complimentary electron scattering measurements in solids; imaging materials and plasma plumes at the limits of 
spatial and time resolution; ultrashort-pulse laser effects; fundamentals of laser ablation and nanoparticle formation in liquids;

- ABLATION APPLICATIONS: ultrafast materials processing by lasers; biological applications of lasers and laser ablation; laser direct writing in bulk of transparent materials; MAPLE and other laser methods of materials processing; - HIGH-POWER LASERS: new results in high power lasers and their applications; promising new laser and optical technologies; new results in diode pumped alkali lasers (DPALS), exciplex pumped alkali laser (XPALS), and noble-gas lasers; advances in microstructured optical fibers and fiber lasers; advances in free electron laser technology;

- NOVEL MATERIALS AND MEASUREMENTS: research facilities and measurement techniques; metamaterials for short-pulse photonic and microwave pulse generation;

- LASER NANO-TECHNOLOGIES: nanoengineering \& materials processing at nanoscale;

- BEAM PROPAGATION AND SPACE APPLICATIONS: microwave and laser power beaming; space debris removal and beyond; phased pulsed fiber laser array applications in space;

- LASER PROPULSION: advanced BEP propulsion concepts; laser ablation propulsion: macro \& micro.

There are several significant motivations for establishing the cross promotion of the two conferences. First, there is a significant overlapping of the topics of two conferences especially in the fields of fundamental mechanisms of laser damage/ablation; laser-surface interactions; high-power lasers. However, the community of LD overlaps with the community of HPLA just a little bit. Therefore, the communities of the two conferences can benefit from information exchange between on conferences and publication plans. Moreover, the cross promotion can assist with increase of attendance of both LD and HPLA conferences. Overall, direct contacts with the HPLA organizers and the crosspromotion can help to establish a good bridge between the two research communities.

The cross promotion has already delivered some good results. Among them, increased submission of manuscripts for the Special Section of Optical Engineering on Laser Damage III should be mentioned: of the 33 manuscripts submitted to this Special Section, 14 were submitted by people of the HPLA community. Of those 14 submissions, several are of exceptional quality. For example, the paper of S. Scharring, J. Wilken, H.-A. Eckel, "Laser-based removal of irregular shaped space debris" is among top downloads of the journal. Also, several presentations were submitted to LD-2016 by people from the HPLA community. In turn the HPLA meeting will be promoted via an overview talk at the opening ceremony of Laser Damage conference, HPLA Call for Papers will be e-mailed to LD participants, and printed copies of HPLA Call for Papers will be made available to LD attendees during the next meeting in 2017.

With those early results, the cross promotion makes the organizers quite optimistic regarding the high potential of mutual support of LD and HPLA conferences that can benefit the both meetings.

\section{Publications}

Concerns were previously expressed by Laser Damage authors regarding copyright issues appeared when results presented at Laser Damage Symposium and published in the Symposium Proceedings were submitted for publication in non-SPIE peer-reviewed journals. To address those concerns, Dr. Vitaly Gruzdev and Dr. Michelle Shinn volunteered as guest editors of Special Section on Laser Damage published in flagman peer reviewed SPIE journal Optical Engineering. The first Special Section was published in volume 51, issue 12: http://opticalengineering.spiedigitallibrary.org/Issue.aspx?JournalID $=92 \&$ \&ssueID $=24711$ \&direction $=\mathrm{P}$

and contained 18 papers selected by peer-reviewers for publication out of 21 submitted manuscripts (Table 2). The papers covered various aspects of laser damage including fundamental mechanisms, influence of defects, measurements of laser-damage thresholds, statistical laws of damage threshold, damage of thin films and optical coatings. Many of those publications were based on the results presented at Laser Damage and on manuscripts published in the Proceedings of Laser Damage Symposium. Other manuscripts were submitted independently via general submission procedure of SPIE journals. That Special Section was recognized as highly successful with multiple downloads and many citations (Fig. 6). That fact motivated the International Program Committee of Laser Damage Symposium to coordinate another Special Section on Laser Damage with editors of Optical Engineering. Result of that effort is the Special Section on Laser Damage-II that was published in volume 53, no. 12 of Optical Engineering in December 2014: http://opticalengineering.spiedigitallibrary.org/Issue.aspx?JournalID=92\&issueID=930112\&direction=P

It contained 16 papers selected out of 21 submissions and covers a broad spectrum of topics related to laser-induced damage. Due to increasing requirements to scientific quality and content of submitted manuscripts, 5 manuscripts were rejected during preparation of that Special Section (Table 2).

Strong interest of the Laser-Damage community to and success of the two previous Special Sections on Laser Damage 
motivated Vitaly Gruzdev and Michelle Shinn to volunteer in editing another Special Section on Laser Damage-III. This Special Section was published in January 2017 in volume 56, no. 1:

http://opticalengineering.spiedigitallibrary.org/issue. aspx?journalid=92\&issueid=935413

It contains record-high number of submissions (33 total) of which 28 were published. This success of the Special Section on Laser Damage III is partly due to the cross promotion with HPLA conference as discussed above.

Table 2. Submission overview of the three Special Sections of Optical Engineering on Laser Damage.

\begin{tabular}{|l|c|c|c|}
\hline Special Section issue & Total submissions & Published & Rejected \\
\hline Laser Damage (v. 51, no. 12, 2012) & 21 & 18 & 3 \\
\hline Laser Damage II (v.53, no. 12, 2014) & 21 & 16 & 5 \\
\hline Laser Damage III (v. 56, no. 1, 2017) & 33 & 28 & 7 \\
\hline
\end{tabular}

\section{In Conclusion}

The location in Boulder, Colorado, during autumn at the venue of the Boulder Millennium Harvest House Hotel and its outstanding facilities and support staff were appreciated by all. All attendees of Laser Damage were easily accommodated with ample opportunity to mingle and socialize. The new venue was highly supportive for fixing the repeating problems with access of registered conference participants to the NIST facilities experienced in 2013-2015

This year the nice weather in Boulder encouraged to take a group picture of all symposium participants outside the National Institute of Atmospheric Research (Boulder, CO) where the traditional Wine and Cheese Reception was held on Tuesday, September 27.

The organizers of the Boulder Damage Symposium look for opportunities to join with other related groups for joint meetings in the future. For example, in 2002 we had a joint meeting with the $7^{\text {th }}$ International Workshop on Laser Beam and Optics Characterization (LBOC), again with no parallel sessions. Also, starting from 2009, Pacific Rim Laser Damage (PLD) symposium is held annually in spring in Shanghai, P. R. China with the topics and the scope completely similar to the topics and scopes of this meeting. We are looking forward to develop fruitful collaboration with PLD meeting in order to join our efforts for better serving the laser-damage community worldwide.

We must also note tireless assistance of SPIE who handle the administrative functions of the symposium. Their presence, experience, resources, and professionalism clearly were made manifest with on-line reservations, payment by credit cards, badges, preparation of the abstract book and pocket programs, preparation and printing this volume of Symposium Proceedings, and on-line document service, to which we may add the social functions - thanks to them, "A good time was had by all."

\section{Acknowledgments}

A number of volunteers help tirelessly with some of the administrate duties necessary to put on a conference of this magnitude. Diane Cline from SPIE took care of all the administrative planning and on-site tasks including setup, registration, and general questions. Bobbie Williams of Lawrence Livermore National Lab helped with the registration pick up and at front desk through the entire meeting. Pat White from SPIE took care of program preparation, invitation letters for international participants, and provided much on-line support for the conference. Joel Shields also from SPIE was responsible for preparation of this volume of the conference proceedings and the publication of the manuscripts into it. Assistance of James Bell (meeting manager) and Jeff Braswell (Marketing) of SPIE is greatly appreciated by organizers of this Laser Damage meeting. 


\begin{tabular}{|c|c|c|c|c|c|c|c|c|}
\hline Vol & Issue & Paper \# & Author(s) & Paper Type & Online & CID & Downloads & Citations \\
\hline 51 & 12 & Dec-12 OE GED-DEC2012 & Gruzdev and Shinn & Guest Editorial & $11 / 9 / 12$ & 121801 & 675 & 0 \\
\hline 51 & 12 & Dec-12 120400SSR & Palm (Marciniak) & Article & $7 / 10 / 12$ & 121802 & 552 & 2 \\
\hline 51 & 12 & Dec-12 120367SSPR & Cho & Article & $7 / 10 / 12$ & 121803 & 294 & 0 \\
\hline 51 & 12 & Dec-12 120366SSPR & Cho & Article & $7 / 10 / 12$ & 121804 & 242 & 0 \\
\hline 51 & 12 & Dec-12 120405SSPR & Gulley & Article & $6 / 27 / 12$ & 121805 & 446 & 5 \\
\hline 51 & 12 & Dec-12 120382SSPRR & Wagner & Article & $7 / 13 / 12$ & 121806 & 245 & 0 \\
\hline 51 & 12 & Dec-12 120493SSPR & Weber & Article & $7 / 9 / 12$ & 121807 & 194 & 6 \\
\hline 51 & 12 & Dec-12 120375SSRR & Apostolova & Article & $8 / 3 / 12$ & 121808 & 307 & 5 \\
\hline 51 & 12 & Dec-12 120381SSR & $\operatorname{Han}(\mathrm{Li})$ & Article & $7 / 19 / 12$ & 121809 & 538 & 4 \\
\hline 51 & 12 & Dec-12 $120406 S S P R$ & Brenk (Rethfeld) & Article & $8 / 22 / 12$ & 121810 & 332 & 3 \\
\hline 51 & 12 & Dec-12 120468SSR & Manenkov & Article & $9 / 18 / 12$ & 121811 & 471 & 4 \\
\hline 51 & 12 & Dec-12 120401SSPRR & Muehlig & Article & $9 / 14 / 12$ & 121812 & 267 & 3 \\
\hline 51 & 12 & Dec-12 120411SSRR & Nikiforov & Article & $9 / 20 / 12$ & 121813 & 93 & 1 \\
\hline 51 & 12 & Dec-12 120377SSRR & Lu & Article & $9 / 26 / 12$ & 121814 & 385 & 4 \\
\hline 51 & 12 & Dec-12 120396SSPRRRR & Ahsan & Article & $9 / 26 / 12$ & 121815 & 319 & 9 \\
\hline 51 & 12 & Dec-12 $120620 S S P R$ & Komolov & Article & $10 / 10 / 12$ & 121816 & 293 & 2 \\
\hline 51 & 12 & Dec-12 $120486 S S P R R$ & Shen & Article & $10 / 10 / 12$ & 121817 & 530 & 16 \\
\hline 51 & 12 & Dec-12 120617SSPR & Stolz & Article & $11 / 28 / 12$ & 121818 & 497 & 0 \\
\hline 51 & 12 & Dec-12 120616SSPRR & Arenberg & Article & $12 / 10 / 12$ & 121819 & 89 & 3 \\
\hline & & & & & & TOTAL & 6769 & 67 \\
\hline 53 & 12 & Dec-14 OE-2014-1208-GED & Gruzdev and Shinn & Guest Editorial & $12 / 22 / 14$ & 122501 & 454 & 0 \\
\hline 53 & 12 & Dec-14 140177SSPR & Carreon & Article & $6 / 11 / 14$ & 122502 & 165 & 0 \\
\hline 53 & 12 & Dec-14 140405SSPR & Balasa & Article & $7 / 1 / 14$ & 122503 & 102 & 0 \\
\hline 53 & 12 & Dec-14 140509SSPR & Papernov & Article & $6 / 25 / 14$ & 122504 & 964 & 1 \\
\hline 53 & 12 & Dec-14 140527SSR & Lu (Ma) & Article & $7 / 1 / 14$ & 122505 & 268 & 1 \\
\hline 53 & 12 & Dec-14 140398R & Rubenchik (Wu) & Article & $7 / 17 / 14$ & 122506 & 226 & 4 \\
\hline 53 & 12 & Dec-14 140456SSPR & Mitchell & Article & $7 / 23 / 14$ & 122507 & 305 & 3 \\
\hline 53 & 12 & Dec-14 140541SSPR & Muehlig & Article & $8 / 11 / 14$ & 122508 & 102 & 0 \\
\hline 53 & 12 & Dec-14 140718SSR & Douti (Gallais) & Article & $8 / 6 / 14$ & 122509 & 251 & 8 \\
\hline 53 & 12 & Dec-14 140531SSR & Baumann (Perram) & Article & $8 / 12 / 14$ & 122510 & 134 & 1 \\
\hline 53 & 12 & Dec-14 140437SSPRR & Hildenbrand (Petrov) & Article & $8 / 21 / 14$ & 122511 & 264 & 6 \\
\hline 53 & 12 & Dec-14 140532SSPR & Gonschior (Klein) & Article & $9 / 2 / 14$ & 122512 & 103 & 0 \\
\hline 53 & 12 & Dec-14 140540SSR & Stratan(Zorila) & Article & $10 / 8 / 14$ & 122513 & 168 & 3 \\
\hline 53 & 12 & Dec-14 140712SSRR & Ding(Wang) & Article & $10 / 6 / 14$ & 122514 & 144 & 0 \\
\hline 53 & 12 & Dec-14 140793SSR & Gruzdev & Article & $10 / 27 / 14$ & 122515 & 312 & 0 \\
\hline 53 & 12 & Dec-14 140754SSPRR & Field & Article & $11 / 6 / 14$ & 122516 & 992 & 0 \\
\hline 53 & 12 & Dec-14 140756SSR & Arenberg & Article & $12 / 2 / 14$ & 122517 & 331 & 0 \\
\hline & & & & & & TOTAL & 5285 & 27 \\
\hline \multicolumn{7}{|c|}{ GRAND TOTAL } & 12054 & 94 \\
\hline
\end{tabular}

Figure 6. A photocopy of a table with download and citation data for the Special Sections on Laser Damage published in 2012 and 2014. Made according to the data provided by the Publishing Department of SPIE as of September 14, 2016.

This year we acknowledge support and sponsorship from Lawrence Livermore National Laboratory (USA) and several companies: Spica Technologies Inc. (USA); Laser Components GmbH (Germany), ZC Optoelectronic Technologies, Ltd (China), Arrow Thin Films (USA); Alpine Research Optics (USA); LIDARIS (Lithuania); KMLabs (USA); Quantel Laser (USA); and REO (USA) for supporting the social events, WiFi access, and refreshments of this meeting. They are separately acknowledged in this volume of conference proceedings. Special acknowledgement is for Femto-Solid Dynamics Laboratory of Dr. Enam Chowdhury of the Ohio State University (USA) for their support of laser-damage competition. Cooperating organizations contributed to success of this Laser Damage meeting are acknowledged: CREOL \& FPCE, College of Optics and Photonics, University of Central Florida (USA); Laser Zentrum Hannover e. V. (Germany); Lawrence Livermore National Laboratory (USA); University of Missouri (USA); Pacific Northwest National Laboratory (USA); Laboratory for Laser Energetics, University of Rochester (USA), Office of Naval Research (USA). 


\section{References}

\section{Books:}

A. J. Glass and A. H. Guenther, eds. Damage in Laser Glass, ASTM Spec. Tech. Pub. 469, ASTM, Philadelphia, PA (1969).

N. Bloembergen, Fundamentals of Damage in Laser Glass, National Materials Advisory Board Publ. NMAB-271, National Academy of Sciences (1970).

N. Bloembergen, High-Power Infrared Laser Windows, National Materials Advisory Board Publ. NMAB-356 (1971).

R. M. Wood, Laser-Induced Damage in Optical Materials, Adam Hilger, Bristol (UK) (1986).

M. J. Weber, ed., Handbook of Laser Science and Technology, Vol. III: Optical Materials, Part 1: Nonlinear Optical Properties/Radiation Damage, CRC, Boca Raton, FL (1986).

M. J. Weber, ed., Handbook of Laser Science and Technology, Vol. IV: Optical Materials, Part 2: Properties, CRC, Boca Raton, FL (1986).

M. J. Weber, ed., Handbook of Laser Science and Technology, Vol. V: Optical Materials, Part 3: Applications, Coatings, and Fabrication, CRC, Boca Raton, FL (1987).

R. M. Wood, Ed., Selected Papers on Laser Damage in Optical Materials, SPIE Milestone Series Vol. MS24, Bellingham, WA (U.S.) (1990).

M. R. Kozlowski, Damage-Resistant Laser Coatings, in Thin Films for Optical Systems, F. Flory, ed., Marcel Dekker, New York, 521-549 (1995).

M. J. Weber, ed., Handbook of Laser Science and Technology, Suppl. 2, Optical Materials, CRC, Boca Raton, FL, (1995).

A. H. Guenther, ed., International Trends in Applied Optics, SPIE Press monograph, Bellingham, Washington, Chapters 1, 3, $8,9,10, \& 12$ (2002).

M. J. Weber, ed., Handbook of Optical Materials, CRC, Boca Raton, FL (2002).

R. M. Wood, The Power and Energy-Handling Capability of Optical Material, Components, and Systems, (Tutoriual Texts in Optical Engineering Vol T'T60 A. R. Weeks Series Editor SPIE Press Bellingham WA) (2003).

R. M. Wood, Laser Induced Damage of Optical Materials (Institute of Physics Publishing, Bistrol, UK) (2003).

C. J. Stolz and F. Y. Génin, Laser Resistant Coatings, in Optical Interference Coatings, N. Kaiser and H. Pulker, eds., Springer-Verlag, Berlin, 310-333 (2003)

D. Ristau, Ed., Laser-Induced Damage in Optical Materials (Francis and Taylor, New York) 551 pages (2014).

\section{Proceedings:}

A. J. Glass and A. H. Guenther, eds., Damage in Laser Materials, Nat. Bur. Stand. (U.S.) Spec. Publ. 341 (1970).

A. J. Glass and A. H. Guenther, Eds., Damage in Laser Materials: 1971, Nat. Bur. Stand. (U.S.) Spec. Publ. 356 (1971).

A. J. Glass and A. H. Guenther, eds., Laser-Induced Damage in Optical Materials: 1972, Nat. Bur. Stand. (U.S.) Spec. Publ. 372 (1972).

A. J. Glass and A. H. Guenther, Eds., Laser-Induced Damage in Optical Materials: 1973, Nat. Bur. Stand. (U.S.) Spec. Publ. 387 (1973).

A. J. Glass and A. H. Guenther, eds., Laser-Induced Damage in Optical Materials: 1974, Nat. Bur. Stand. (U.S.) Spec. Publ. 414 (1974).

A. J. Glass and A. H. Guenther, eds., Laser-Induced Damage in Optical Materials: 1975, Nat. Bur. Stand. (U.S.) Spec. Publ. 435 (1975).

A. J. Glass and A. H. Guenther, eds., Laser-Induced Damage in Optical Materials: 1976, Nat. Bur. Stand. (U.S.) Spec. Publ. 462 (1976).

A. J. Glass and A. H. Guenther, eds., Laser-Induced Damage in Optical Materials: 1977, Nat. Bur. Stand. (U.S.) Spec. Publ. 509 (1977).

A. J. Glass and A. H. Guenther, eds., Laser-Induced Damage in Optical Materials: 1978, Nat. Bur. Stand. (U.S.) Spec. Publ. 541 (1978).

H. E. Bennett, A. J. Glass, A. H. Guenther, and B. E. Newnam, eds., Laser-Induced Damage in Optical Materials: 1979 , Nat. Bur. Stand. (U.S.) Spec. Publ. 568 (1979).

H. E. Bennett, A. J. Glass, A. H. Guenther, and B. E. Newnam, eds., Laser-Induced Damage in Optical Materials: 1980, Nat. Bur. Stand. (U.S.) Spec. Publ. 620 (1981).

H. E. Bennett, A. J. Glass, A. H. Guenther, and B. E. Newnam, eds., Laser-Induced Damage in Optical Materials: 1981 , Nat. Bur. Stand. (U.S.) Spec. Publ. 638 (1983).

H. E. Bennett, A. H. Guenther, D. Milam, and B. E. Newnam, eds., Laser-Induced Damage in Optical Materials: 1982, Nat. Bur. Stand. (U.S.) Spec. Publ. 669 (1984).

H. E. Bennett, A. H. Guenther, D. Milam, and B. E. Newnam, eds., Laser-Induced Damage in Optical Materials: 1983 , Nat.

xxvi 
Bur. Stand. (U.S.) Spec. Publ. 688 (1985).

H. E. Bennett, A. H. Guenther, D. Milam, and B. E. Newnam, eds., Laser-Induced Damage in Optical Materials: 1984 , Nat. Bur. Stand. (U.S.) Spec. Publ. 727 (1986).

H. E. Bennett, A. H. Guenther, D. Milam, and B. E. Newnam, eds., Laser-Induced Damage in Optical Materials: 1985, Nat. Bur. Stand. (U.S.) Spec. Publ. 746 (1987).

H. E. Bennett, A. H. Guenther, D. Milam, and B. E. Newnam, eds., Laser-Induced Damage in Optical Materials: 1986, Nat. Bur. Stand. (U.S.) Spec. Publ. 752 (1987).

H. E. Bennett, A. H. Guenther, D. Milam, B. E. Newnam, and M. J. Soileau, eds., Laser-Induced Damage in Optical Materials: 1987, Nat. Bur. Stand. (U.S.) Spec. Publ. 756 (1988).

H. E. Bennett, A. H. Guenther, B. E. Newnam, and M. J. Soileau, eds., Laser-Induced Damage in Optical Materials: 1988, Nat. Bur. Stand. (U.S.) Spec. Publ. 775 (1989).

H. E. Bennett, L. L. Case, A. H. Guenther, B. E. Newnam, and M. J. Soileau, eds., Laser-Induced Damage in Optical Materials: 1989, NIST (U.S.) Spec. Publ. 801, ASTM STP 1117 and Proc. SPIE 1438 (1989).

H. E. Bennett, L. L. Case, A. H. Guenther, B. E. Newnam, and M. J. Soileau, eds., Laser-Induced Damage in Optical Materials: 1990, ASTM STP 1141 and Proc. SPIE 1441 (1991).

H. E. Bennett, L. L. Case, A. H. Guenther, B. E. Newnam, and M. J. Soileau, eds., Laser-Induced Damage in Optical Materials: 1991, Proc. SPIE 1624 (1992).

H. E. Bennett, L. L. Case, A. H. Guenther, B. E. Newnam, and M. J. Soileau, eds., Laser-Induced Damage in Optical Materials: 1992, Proc. SPIE 1848 (1993).

H. E. Bennett, L. L. Case, A. H. Guenther, B. E. Newnam, and M. J. Soileau, eds., Laser-Induced Damage in Optical Materials: 1993, Proc. SPIE 2114 (1994).

H. E. Bennett, A. H. Guenther, M. R. Kozlowski, B. E. Newnam, and M. J. Soileau, eds., Laser-Induced Damage in Optical Materials: 1994, Proc. SPIE 2428 (1995).

H. E. Bennett, A. H. Guenther, M. R. Kozlowski, B. E. Newnam, and M. J. Soileau, eds., Laser-Induced Damage in Optical Materials: 1995, Proc. SPIE 2714 (1996).

H. E. Bennett, A. H. Guenther, M. R. Kozlowski, B. E. Newnam, and M. J. Soileau, eds., Laser-Induced Damage in Optical Materials: 1996, Proc. SPIE 2966 (1997).

G. J. Exarhos, A. H. Guenther, M. R. Kozlowski, and M. J. Soileau, eds., Laser-Induced Damage in Optical Materials: 1997, Proc. SPIE 3244 (1998).

G. J. Exarhos, A. H. Guenther, M. R. Kozlowski, K. Lewis, and M. J. Soileau, eds., Laser-Induced Damage in Optical Materials: 1998, Proc. SPIE 3578 (1999).

G. J. Exarhos, A. H. Guenther, M. R. Kozlowski, K. Lewis, and M. J. Soileau, eds., Laser-Induced Damage in Optical Materials: 1999, Proc. SPIE 3902 (2000).

G. J. Exarhos, A. H. Guenther, M. R. Kozlowski, K. Lewis, and M. J. Soileau, eds., Laser-Induced Damage in Optical Materials: 2000, Proc. SPIE 4347 (2001).

G. J. Exarhos, A. H. Guenther, K. Lewis, M. J. Soileau, and C. J. Stolz eds., Laser-Induced Damage in Optical Materials: 2001, Proc. SPIE 4679 (2002).

G. J. Exarhos, A. H. Guenther, K. Lewis, N. Kaiser, M. J. Soileau, and C. J. Stolz eds., Laser-Induced Damage in Optical Materials: 2002, Proc. SPIE 4932 (2003).

G. J. Exarhos, A. H. Guenther, K. Lewis, N. Kaiser, M. J. Soileau, and C. J. Stolz eds., Laser-Induced Damage in Optical Materials: 2003, Proc. SPIE 5273 (2004).

G. J. Exarhos, A. H. Guenther, K. Lewis, N. Kaiser, M. J. Soileau, and C. J. Stolz eds., Laser-Induced Damage in Optical Materials: 2004, Proc. SPIE 5647 (2005).

G. J. Exarhos, A. H. Guenther, K. Lewis, D. Ristau, M. J. Soileau, and C. J. Stolz eds., Laser-Induced Damage in Optical Materials: 2005, Proc. SPIE 5991 (2006).

G. J. Exarhos, A. H. Guenther, K. Lewis, D. Ristau, M. J. Soileau, and C. J. Stolz eds., Laser-Induced Damage in Optical Materials: 2006, Proc. SPIE 6403 (2007).

G. J. Exarhos, D. Ristau, M. J. Soileau, and C. J. Stolz eds., Laser-Induced Damage in Optical Materials: 2007, Proc. SPIE 6720 (2008).

G. J. Exarhos, D. Ristau, M. J. Soileau, and C. J. Stolz eds., Laser-Induced Damage in Optical Materials: 2008, Proc. SPIE $7132(2009)$.

G. J. Exarhos, V. E. Gruzdev, D. Ristau, M. J. Soileau, and C. J. Stolz eds., Laser-Induced Damage in Optical Materials: 2009, Proc. SPIE 7504 (2010).

G. J. Exarhos, V. E. Gruzdev, J. A. Menapace, D. Ristau, and M. J. Soileau, eds., Laser-Induced Damage in Optical Materials: 2010, Proc. SPIE 7842 (2011).

G. J. Exarhos, V. E. Gruzdev, J. A. Menapace, D. Ristau, and M. J. Soileau, eds., Laser-Induced Damage in Optical Materials: 2011, Proc. SPIE 8190 (2012). 
G. J. Exarhos, V. E. Gruzdev, J. A. Menapace, D. Ristau, and M. J. Soileau, eds., Laser-Induced Damage in Optical Materials: 2012, Proc. SPIE 8530 (2013).

G. J. Exarhos, V. E. Gruzdev, J. A. Menapace, D. Ristau, and M. J. Soileau, eds., Laser-Induced Damage in Optical Materials: 2013, Proc. SPIE 8885 (2014).

G. J. Exarhos, V. E. Gruzdev, J. A. Menapace, D. Ristau, and M. J. Soileau, eds., Laser-Induced Damage in Optical Materials: 2014, Proc. SPIE 9237 (2015).

G. J. Exarhos, V. E. Gruzdev, J. A. Menapace, D. Ristau, and M. J. Soileau, eds., Laser-Induced Damage in Optical Materials: 2015, Proc. SPIE 9632 (2016).

G. J. Exarhos, V. E. Gruzdev, J. A. Menapace, D. Ristau, and M. J. Soileau, eds., Laser-Induced Damage in Optical Materials: 2016, Proc. SPIE 10014 (2017).

\section{Compact Discs:}

A. H. Guenther, ed., Laser-Induced Damage in Optical Materials: Collected papers 1969-1998 (a three CD-ROM set available from SPIE, P.O. Box 10, Bellingham, WA 98227-0010) (1999).

A. H. Guenther, ed., Laser-Induced Damage in Optical Materials: Collected papers 1999-2003 (CD-ROM available from SPIE, P.O. Box 10, Bellingham, WA 98227-0010) (2004).

Selected SPIE Papers on CD-ROM: Laser-Induced Damage in Optical Materials. 1969-2008: 40 years of Boulder Damage Symposium, v. 50 (CD-ROM available from SPIE, P.O. Box 10, Bellingham, WA 98227-0010) (2008).

Selected SPIE Papers on CD-ROM: Laser-Induced Damage in Optical Materials. Collected Papers, 2009-2010, v. 52 (CD-ROM available from SPIE, P.O. Box 10, Bellingham, WA 98227-0010) (2010).

Selected SPIE Papers on CD-ROM: Laser-Induced Damage in Optical Materials: 45 th Anniversary Collection (20092013), v. 57 (CD-ROM available from SPIE, P.O. Box 10, Bellingham, WA 98227-0010) (2010).

\section{Journal articles:}

A. J. Glass and A. H. Guenther, eds., Laser-Induced Damage in Optical Materials: A conference Report, Appl. Opt. 13 (1): $74-88$ (1974).

A. J. Glass and A. H. Guenther, eds., Laser-Induced Damage in Optical Materials: $6^{\text {th }}$ ASTM Symposium, Appl. Opt. 14 (3): 698-715 (1975).

A. J. Glass and A. H. Guenther, eds., Laser-Induced Damage in Optical Materials: $7^{\text {th }}$ ASTM Symposium, Appl. Opt. 15 (6): 1510-1529 (1976).

A. J. Glass and A. H. Guenther, eds., Laser-Induced Damage in Optical Materials:87 th ASTM Symposium, Appl. Opt. 16 (5): 1214-1231 (1977).

A. J. Glass and A. H. Guenther, eds., Laser-Induced Damage in Optical Materials: $9^{\text {th }}$ ASTM Symposium, Appl. Opt. 17 (6): 2386-2411 (1978).

A. J. Glass and A. H. Guenther, eds., Laser-Induced Damage in Optical Materials: $10^{\text {th }}$ ASTM Symposium, Appl. Opt. 18 (13): 2212-2229 (1979).

H. E. Bennett, A. J. Glass, A. H. Guenther, and B. E. Newnam, eds., Laser-Induced Damage in Optical Materials: $11^{\text {th }}$ ASTM Symposium, Appl. Opt. 19 (14): 2375-2397 (1980).

H. E. Bennett, A. J. Glass, A. H. Guenther, and B. E. Newnam, eds., Laser-Induced Damage in Optical Materials: $12^{\text {th }}$ ASTM Symposium, Appl. Opt. 20 (17): 3003-3019 (1981).

H. E. Bennett, A. H. Guenther, D. Milam, and B. E. Newnam, eds., Laser-Induced Damage in Optical Materials: $13^{\text {th }}$ ASTM Symposium, Appl. Opt. 22 (20): 3276-3296 (1983).

H. E. Bennett, A. H. Guenther, D. Milam, and B. E. Newnam, eds., Laser-Induced Damage in Optical Materials: $14^{\text {th }}$ ASTM Symposium, Appl. Opt. 23 (21): $3782-3795$ (1984).

H. E. Bennett, A. H. Guenther, D. Milam, and B. E. Newnam, eds., Laser-Induced Damage in Optical Materials: $15^{\text {th }}$ ASTM Symposium, Appl. Opt. 25 (2): 258-275 (1986).

H. E. Bennett, A. H. Guenther, D. Milam, and B. E. Newnam, eds., Laser-Induced Damage in Optical Materials: $16^{\text {th }}$ ASTM Symposium, Appl. Opt. 26 (5): 813-827 (1987).

A. H. Guenther, "Optics damage constrains laser design and performance," Laser Focus World, 29, 83-87, 1992.

A. H. Guenther, "Previewing the Boulder Damage Symposium," Lasers and Optronics 12, 25-26,1993.

A. H. Guenther, "Laser-Induced Damage in Optical Materials at the October 6-8, 1997 Symposium on Optical Materials for High-Power Lasers (Boulder Damage Symposium), Boulder, Colorado” J. Laser Appl. 9, 261-266,1997. 